\title{
Estimation of the Reproduction Number for COVID-19 Based on Latest Vaccination Results and the Timing for Herd-Immunity: Prospect for 2021
}

\author{
Steven Suan Zhu ${ }^{1, *}$ and Enahoro Iboi ${ }^{2}$ \\ ${ }^{1}$ School of Engineering and Applied Science, Computer Science, Washington University, St.Louis, MO 63130 USA. \\ ${ }^{2}$ Department of Mathematics, Spelman College, Atlanta, GA 30314 USA.
}

March 25, 2021

\begin{abstract}
This study examined four countries Israel, United States, United Kingdom, and Serbia and present their possible vaccination trajectories into 2021. We found that populations in all the four countries are relaxing and taking the advantage of the benefit of an increasingly immunized community hence, experiencing a rising phase of $\mathcal{R}_{c}(t)$. The United States is of particular concern, due to its fast rising $\mathcal{R}_{c}(t)$ in comparison to other countries, potentially generating another wave of infection. Due to aggressive vaccination program, continued implementation of restrictive measures, or both, in all countries we analyzed, present a cautiously optimistic outlook at controlling the pandemic toward the latter part of 2021. We also found that despite a significant fraction of the population in selected countries being immunized, no countries other than Israel has its $\mathcal{R}_{c}(t)$ reached its intrinsic $\mathcal{R}_{0}$ value. Based on our proposed methodology for deriving $\mathcal{R}_{0}$, our prediction shows that Israel's indigenous COVID-19 daily $\mathcal{R}_{0}$ is approximately 2.2 based on its latest data.
\end{abstract}

Keywords: COVID-19, Control Reproduction Number, Vaccination, Efficacy, First Dose, Second Dose, Endemic Equilibrium, Herd immunity, Vaccination Matrix

\section{Introduction}

When COVID-19 Pandemic Struck the world in late December 2019, organizations, companies, and governments raced for the development of vaccine against the disease. Throughout 2020, more than a few dozens of vaccines were under development. Toward the fall of 2020, several vaccines entered the late phase of clinical trial III. [1] Then, Russia became the first nation to put its self-developed Sputnik $V$ vaccine into usage domestically [2]. On December 2, 2020, the United Kingdom (UK) gave regulatory approval for Pfizer-BioNTech vaccine, [3, 4] becoming the first country in the Western world to approve the use of any COVID-19 vaccine on humans. By end of 2020, many countries including the United States (US) and the European Union (EU) have authorized or approved the Pfizer-BioNTech vaccine[5]. Bahrain and the United Arab Emirates (UAE) granted emergency marketing authorization for BBIBP-CorV, manufactured by Sinopharm from China [6, 7]. Moderna which is the first RNA vaccine was approved in the US in late December 2020 [8]. By the beginning of 2021, a significant number of countries around the world has at least implemented some vaccination delivery program to its citizens. Among them, several countries such as Israel, Seychelles, UAE, US, UK, Chile, and Serbia stood out from the rest with rapid and ambitious vaccination strategies.

The objective of this study is to use the rich available vaccination data accumulated during the early months of 2021 from the aforementioned countries to gain better understanding of the effectiveness of the vaccines at curbing

\footnotetext{
${ }^{*}$ Corresponding author: Email: suan.zhu@wustl.edu
} 
the pandemic and human behavioral changes in response to the vaccine. Israel was selected since it lead others in terms of vaccination administration on its citizens. US was also selected due to its absolute population and infection size, UK and Serbia are included since they are the most aggressive countries in terms of its vaccination program in Europe. We will put our theoretical model to test with real world data, and make predictions about the progression of the pandemics in the presence of vaccinations, the timing of herd immunity, and ultimately estimate the $\mathcal{R}_{0}$ value of COVID-19 infection. Many mathematical models have been proposed for modeling COVID-19 and its subsequent vaccination program (see for instance $[9,10,11,12,13,14,15,16,17,18,19,20]$ ). In general, epidemic models broadly explores the evolution of disease processes over time, and explore patterns and correlations in data using regressions and time series analysis. Epidemic models are divided into deterministic, stochastic, network, and agent based. Models described as continuous in time uses differential equations (compartmental models), while discrete-time models uses the difference equations $[19,18,20]$.

In our study, we are adopting a hybrid modeling approach, involving dynamic and statistical modeling. We use statistical regression to derive the time dependent $\mathcal{R}_{c}(t)$, which is the $\mathcal{R}_{0}$ value change in response to the implementation of control measures to account for the gradual refinement in, or improvement of, these control measures. We found, based on earlier works with fairly good approximation, despite the non-autonomous characteristics of time dependence of parameters such as $\mathcal{R}_{c}$ related to the implementation of control measures [21], can be worked around without devolving into the intricate inner working interactions by the simple assumption, that a momentum is gained so that the cooperation and change of behaviors between the citizens and the governments is maintained once quarantine isolation measures takes in place [22]. As a result, a measure tends to be enforced in place steadily for a long period of time rather than dynamically changes on a weekly or even daily basis [22]. In a sense, it is the same assumption used in economic theory, that one can assume the participants are rational players act cautiously based on their assessment of the situation at the time. Therefore, the trend observed from the extrapolation from historical time series can be applied for future predictions. We adopt a deterministic discrete-time model using difference equations in units of day to predict the epidemic progression of each country through simulation. No stochastic model is necessary since all countries under study has a population size of at least 7 million.

In our previous papers [23, 24, 25, 26, 27], we have outlined this deterministic model for viral infection and its instantiation for COVID-19 in particular. The final infection ratio within any given population without any artificial intervention and have shown that the final infection ratio in a natural, non-interfered pandemic must fall within a specified lower and upper bound given by $1-\frac{1}{\mathcal{R}_{0}^{2}} \leq F_{R} \leq 2\left(1-\frac{1}{\mathcal{R}_{0}}\right)$, where $\mathcal{R}_{0}$ is the intrinsic $\mathcal{R}_{0}$ value of the disease. We also outlined that all pandemic progression can be summarized within 4 possible scenarios:

1. fixed $\mathcal{R}_{0}+$ fixed cumulative vaccination $V(t)$, minimal lockdown measures and no vaccinations,

2. variable $\mathcal{R}_{c}(t)+$ fixed cumulative vaccination $V(t)$, lockdown measures with no vaccinations,

3. fixed $\mathcal{R}_{0}+$ variable cumulative vaccination $V(t)$, minimal lockdown measures but with constant vaccination rates

4. variable $\mathcal{R}_{c}(t)+$ variable cumulative vaccination $V(t)$, lockdown measures and constant vaccination rates.

This study focus on the last scenario since we found that in all countries we analyzed, the pandemic falls under the last scenario, that is, variable $\mathcal{R}_{c}(t)+$ variable cumulative vaccination $V(t)$.

The remainder of the work in this paper is organized as follows. Section 2 outlines the statistical method for deriving $\mathcal{R}_{c}(t)$ and the construction of deterministic discrete-time model using difference equations in units of day, and the statistical derivation of $\mathcal{R}_{0}$ based on known $\mathcal{R}_{c}(t)$, susceptible ratio $S(t)$, and daily observed infection $I^{d}(t)$. Section 3 outlines pandemic projections for Israel, the US, UK, and Serbia. Section 4 and 5 outlines discussions and conclusions regarding the model. 
medRxiv preprint doi: https://doi.org/10.1101/2021.03.25.21254362; this version posted March 26, 2021. The copyright holder for this preprint (which was not certified by peer review) is the author/funder, who has granted medRxiv a license to display the preprint in perpetuity.

It is made available under a CC-BY-NC-ND 4.0 International license .

\section{Materials and Methods}

\subsection{Derivation of the control $\mathcal{R}_{c}(t)$ and the construction of deterministic, recursive, discrete-time simulation model}

The immunity ratio within the entire region of interest will now be derived. Let $N$ be the total population of our region of interest and $I(t)$ be the cumulative number of infections observed on day $t$. Let $V_{1}\left(t-t_{\epsilon}\right)$ be the cumulative population that received at least one dose by day $t$ and $V_{2}\left(t-t_{\epsilon}\right)$ be the cumulative population that received 2 doses, where $t$ is the current day. The parameter $\epsilon$ represent the delay of the onset of antibodies after immunization, so that the effective immunized population at the current day observed always correlate with cumulative immunized population size at an earlier date. Let $e_{1}$ be the efficacy for inducing antibodies based immunity with 1 dosage, and $e_{2}$ is the efficacy for inducing antibodies based immunity with 2 dosages so that

$$
e_{2}=e_{1}+\left(1-e_{1}\right) e_{1}
$$

The immunity ratio $E(t)$ within the entire population can be computed based on the following equation:

$$
E(t)=\frac{I(t)+\left(V_{1}\left(t-t_{\epsilon}\right)-V_{2}\left(t-t_{\epsilon}\right)\right) \times e_{1}+V_{2}\left(t-t_{\epsilon}\right) \times e_{2}}{N}
$$

We denote $V_{1}^{d}(t)$ to be the daily vaccination number, which is the difference between the cumulative number of vaccinations on any consecutive days. Hence,

$$
V_{1}^{d}(t)=V_{1}(t)-V_{1}(t-1)
$$

Similarly, let $I^{d}(t)$ represent the daily new infections, then

$$
I^{d}(t)=I(t)-I(t-1) .
$$

The control reproduction number $\mathcal{R}_{c}(t)$ which is defined as the daily rate of change in the number of new infections observed divided by the ratio of those who remains susceptible is given by

$$
\mathcal{R}_{c}(t)=\frac{\frac{I^{d}(t)-I^{d}(t-1)}{I^{d}(t-1)-I^{d}(t-2)}}{1-E(t)},
$$

Using the 7 days moving average $\overline{I^{d}(t)}$ instead of 1 day to derive the daily rate of change to smooth the cyclic fluctuations observed in COVID-19 cases,[28] equation 2.5 becomes

$$
\mathcal{R}_{c}(t)=\frac{\overline{\frac{I^{d}(t)}{I^{d}(t-1)}-\overline{I^{d}(t-1)}}-\overline{I^{d}(t-2)}}{1-E(t)}
$$

Based on the historical time series of $\mathcal{R}_{c}(t)$, which can be expressed as:

$$
\begin{gathered}
t=(0,1, \ldots t-2, t-1, t) \\
y=\left(\mathcal{R}_{c}(0), \mathcal{R}_{c}(1), \ldots \mathcal{R}_{c}(t-2), \mathcal{R}_{c}(t-1), \mathcal{R}_{c}(t)\right)
\end{gathered}
$$

we find the best fit (polynomial or linear fit) that best extrapolate future trends as:

$$
\begin{aligned}
& \mathcal{R}_{c}(t)=y=a t^{b}+c \\
& \mathcal{R}_{c}(t)=y=a t+c
\end{aligned}
$$

which generalize $\mathcal{R}_{c}(t)$ into a closed form by incorporating the past and projecting into the future. 
The simulation will be carried out using the following recursive equation:

$$
\begin{aligned}
& I_{S}^{d}(t)=I_{S}^{d}(t-1) \times R_{C}(t-1) \times S(t-1), \\
& I_{S}(t)=I_{S}(t-1)+I_{S}^{d}(t), \\
& V_{1}\left(t-t_{\epsilon}\right)=V_{1}\left(t-t_{\epsilon}-1\right)+V_{1}^{d}\left(t-t_{\epsilon}\right), \\
& V_{2}\left(t-t_{\epsilon}\right)=V_{2}\left(t-t_{\epsilon}-1\right)+V_{2}^{d}\left(t-t_{\epsilon}\right), \\
& E(t)=\frac{I_{S}(t)+\left(V_{1}\left(t-t_{\epsilon}\right)-V_{2}\left(t-t_{\epsilon}\right)\right) \times e_{1}+V_{2}\left(t-t_{\epsilon}\right) \times e_{2}}{N}, \\
& S(t)=1-E(t),
\end{aligned}
$$

where the daily infection $I_{S}^{d}(t)$ is first computed for the simulated results based on previous day's infection and the latest change on control $\mathcal{R}_{c}(t-1)$ as well as the remaining number of susceptible. Then the cumulative number of infected $I_{S}(t)$ with $I_{S}^{d}(t)$ are updated. Next, the cumulative vaccination number $V_{1}\left(t-t_{\epsilon}\right)$ and $V_{2}\left(t-t_{\epsilon}\right)$ are updated with daily vaccination increase. Further, the current effective immunization ratio $E(t)$ is updated. Finally, the remaining susceptible ratio is obtained from $E(t)$.

\subsection{Derivation of Intrinsic $\mathcal{R}_{0}$ from $\mathcal{R}_{c}(t), S(t)$, and daily infection $I^{d}(t)$}

For a disease such as COVID-19, we do not know the upper bound of $\mathcal{R}_{0}$ and there is no guarantee that it can be derived even when $100 \%$ immunity is achieved. To see why, we define the first day when vaccinations are introduced as $t_{F}$ and the last day when vaccinations are completed as $t_{L}$, so that all days of $t$ falls within $t_{F} \leq t \leq$ $t_{L}$, then imagining that dosages are administered at a certain rate $V^{d}(t)$, infection are introduced at a certain rate $I^{d}(t)$, and the control $\mathcal{R}_{c}(t)$ is also rising at a certain rate. So the controlled endemic equilibrium is:

$$
\frac{1}{S(t)}
$$

That is, the inverse of the remaining susceptible population ratio, and $0 \leq S(t) \leq 1$. The remaining susceptible population ratio is expressed as:

$$
S(t)=1-E(t)
$$

When the controlled endemic equilibrium brought by $\frac{1}{S(t)}$ exceeds the $\mathcal{R}_{c}(t)$ rate at all times $t_{F} \leq t \leq t_{L}$, the entire population becomes immunized before its behavior returned to complete normalcy, so that:

$$
\mathcal{R}_{c}\left(t_{L}\right) \leq \mathcal{R}_{0}
$$

In the most extreme case, all vaccinations are delivered instantly to all populations while the entire population was under a complete lockdown with a daily control $\mathcal{R}_{c}<1$ as:

$$
\frac{\mathcal{R}_{c}\left(t_{F}\right)}{S\left(t_{F}\right)}<1
$$

When the society returned to normalcy, no additional daily $\mathcal{R}_{c}$ can be observed since no additional cases are reported. In fact, no additional cases can be observed even before $t_{L}$ is reached. Therefore, the final derived $\mathcal{R}_{0}<1$ based on $\mathcal{R}_{c}$. Nevertheless, in general, full vaccinations are achieved after a period of time. During this time, control $\mathcal{R}_{c}$ steadily rises but yet to reach its intrinsic value $\mathcal{R}_{0}$. As a result, at the end of vaccination, one can only predict that $\mathcal{R}_{0} \geq \mathcal{R}_{c}$. When vaccination program lasts long enough so that there is enough time for $\mathcal{R}_{c}(t)$ reaching its intrinsic ceiling value of $\mathcal{R}_{0}$. Then it can be observed based on the discrepancy between the projected 
medRxiv preprint doi: https://doi.org/10.1101/2021.03.25.21254362; this version posted March 26, 2021. The copyright holder for this preprint (which was not certified by peer review) is the author/funder, who has granted medRxiv a license to display the preprint in perpetuity.

It is made available under a CC-BY-NC-ND 4.0 International license .

path and the actual path. We define that there exists a time $t_{0}$ in which $t_{F}<t_{0}<t_{L}$, so that any time $t$ occurs later than $t_{0}$ as $t>t_{0}$, we have:

$$
\frac{\frac{\overline{I^{d}(t)}-\overline{I^{d}(t-1)}}{\bar{I}^{d}(t-1)}-\overline{I^{d}(t-2)}}{S(t)}<\mathcal{R}_{c}(t)
$$

That is, the observed daily infection $\mathcal{R}_{C}$ values starts to fall below the expected continually rising $\mathcal{R}_{c}(t)$ curve. In other words, $\mathcal{R}_{c}(t)$ is no longer increasing and the intrinsic $\mathcal{R}_{0}$ value is reached. We can also detect such change by:

$$
\begin{gathered}
\overline{I^{d}(t)}<I_{S}^{d}(t) \\
I_{S}^{d}(t)=I_{S}^{d}(t-1) \times \mathcal{R}_{c}(t-1) \times S(t-1)
\end{gathered}
$$

That is, the number of reported infections starts to fall below the number predicted for a continually rising $\mathcal{R}_{c}(t)$ curve. Where $I_{S}^{d}(t-1)$ is the recursively simulated/expected infection numbers on day $t-1$, the product with $\mathcal{R}_{c}(t-1) \times S(t-1)$ yields the recursively simulated/expected infection numbers on day $t$ as $I_{S}^{d}(t)$. The earliest date in which the intrinsic $\mathcal{R}_{0}$ can be derived is then $t=t_{0}$ :

$$
\frac{\frac{\overline{I^{d}\left(t_{0}\right)}-\overline{I^{d}\left(t_{0}-1\right)}}{\overline{I^{d}\left(t_{0}-1\right)}-\overline{I^{d}\left(t_{0}-2\right)}}}{S\left(t_{0}\right)}=\mathcal{R}_{0}
$$

But one should able to derive $\mathcal{R}_{0}$ for any $t>t_{0}$ and certainly we have:

$$
\lim _{t \rightarrow t_{L}} \frac{\frac{\overline{I^{d}(t)}-\overline{I^{d}(t-1)}}{S(t-1)}-\overline{I^{d}(t-2)}}{S(t)}=\mathcal{R}_{0}
$$

Figure 2.1 shows a model simulation, with a $\mathcal{R}_{c}(t)=0.0002 t^{2}+1$, and an intrinsic $\mathcal{R}_{0}=2$ and initial seed infection size $=40$ and total population of 10000 , both graph shows the endemic equilibrium required by $\mathcal{R}_{c}(t)$ and the remaining susceptible ratio $S(t)$ at any given time. In the top graph, vaccination at a rate of 90 daily is fast enough so that the last infection is observed well before $\mathcal{R}_{c}(t)$ returned to its intrinsic endemic equilibrium $\frac{1}{\mathcal{R}_{0}}$. As a result, the remaining susceptible ratio is reduced solely by vaccination and true $\mathcal{R}_{0}$ can not be obtained due to an absence of observable infection. In the bottom graph, vaccination at a rate of 5 daily is slow enough so that the last infection occurs well after $\mathcal{R}_{c}(t)$ returned to its intrinsic endemic equilibrium $\frac{1}{\mathcal{R}_{0}}$. As a result, there exists an observation window to confirm the true value of $\mathcal{R}_{0}$. 
medRxiv preprint doi: https://doi.org/10.1101/2021.03.25.21254362; this version posted March 26, 2021. The copyright holder for this preprint (which was not certified by peer review) is the author/funder, who has granted medRxiv a license to display the preprint in perpetuity.

It is made available under a CC-BY-NC-ND 4.0 International license .
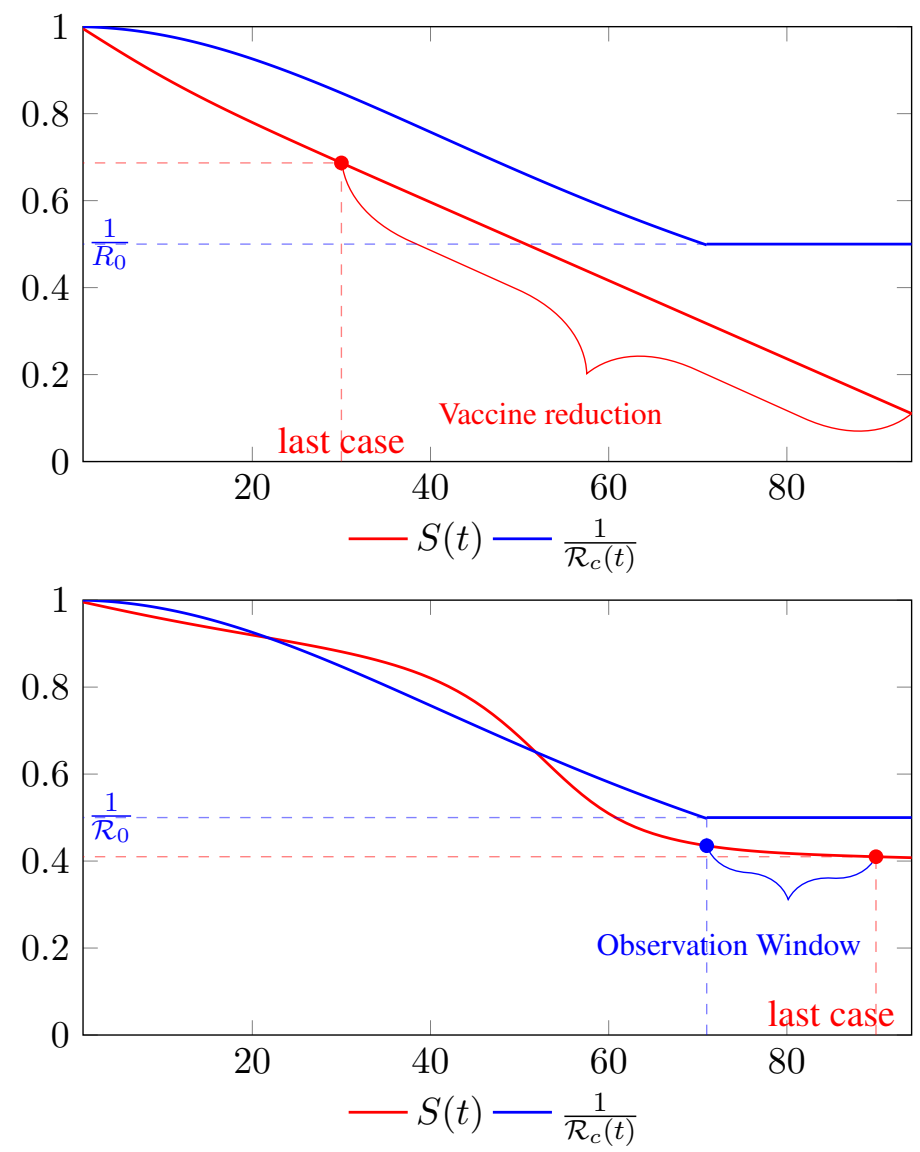

Figure 2.1

Figure 2.2 shows a model simulation, with a $\mathcal{R}_{c}(t)=0.00077 t^{2}+1$, and an intrinsic $\mathcal{R}_{0}=2$ and initial seed size $=100$, and from left to right: $V^{d}(t)=400, V^{d}(t)=200, V^{d}(t)=150, V^{d}(t)=110$, and $V^{d}(t)=4$, so each day 400, 200, 150,110, and 4 people vaccinated so immediately removed from remaining susceptible respectively. the final daily infection number $I_{S}^{d}(t)$ is displayed by calendar days. The gray line indicates that given enough time $t \geq t_{0}=37$, the rising $\mathcal{R}_{c}(t)$ has returned the control $\mathcal{R}_{c}$ back to $\mathcal{R}_{0}$. Only under $V^{d}(t)=110$, and $V^{d}(t)=4$, vaccination scheme was slow enough so that $\mathcal{R}_{0}$ can be effectively derived based on non-zero values of infections. Under cases $V^{d}(t)=400, V^{d}(t)=200$, and $V^{d}(t)=150$, zero infections are reported before the rising $\mathcal{R}_{c}(t)$ has returned the control $\mathcal{R}_{c}$ back to $\mathcal{R}_{0}$. Therefore, aggressive vaccination results in last infection occurs before $\mathcal{R}_{c}(t)$ returned to its $\mathcal{R}_{0}$ value. Since $\mathcal{R}_{c}$ values can be derived only based on daily infection changes, once zero infection is reached, there is no way to know the true $\mathcal{R}_{0}$ of the disease. Under those scenarios, $\mathcal{R}_{c}\left(t_{L}\right)<\mathcal{R}_{0}$. 


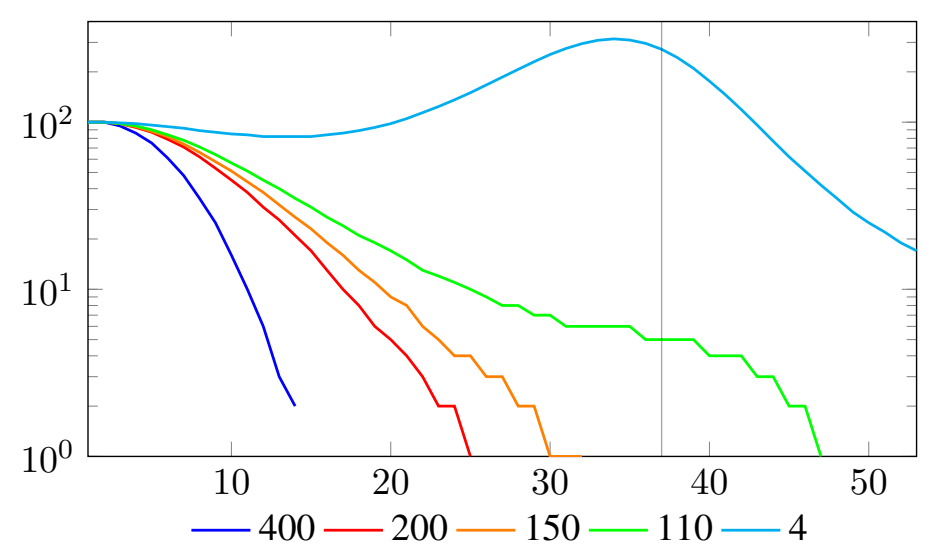

Figure 2.2: In this model simulation with aggressive vaccination strategy $>110$ vaccinations daily, the last infection is observed before day 36 , when $\mathcal{R}_{C}(t)$ returned to its $\mathcal{R}_{c}\left(t_{L}\right)$

Figure 2.3 shows the final daily infection number $I_{S}^{d}(t)$ based on $v_{c}(t)$ curves, one is capped at intrinsic $\mathcal{R}_{0}=2$ and the other is capped at intrinsic $\mathcal{R}_{0}=10$, the one capped at higher $\mathcal{R}_{0}$ experienced 2 waves of infection as rising $\mathcal{R}_{c}(t)$ repeatedly exceeds $V_{0}^{d}(t)$. We also show that there exists a $t_{0}=38$, for which $t_{F}<t_{0}<t_{L}$, and $\overline{I^{d}(t)}<I_{S}^{d}(t)$ in which we assume that the $\mathcal{R}_{c}(t)$ curve capped at $\mathcal{R}_{0}=2$ represents $\overline{I^{d}(t)}$, and the other is capped at intrinsic $\mathcal{R}_{0}=10$ represents $I_{S}^{d}(t)$, despite the fact that both are $I_{S}^{d}(t)$.

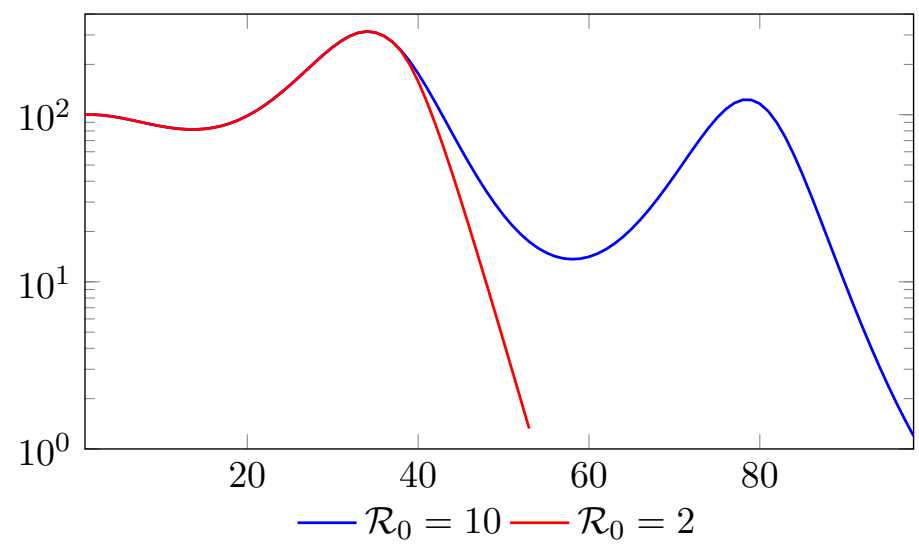

Figure 2.3: In this model simulation, 2 waves of infections is observed for $\mathcal{R}_{0}=10$ compared to only 1 for $\mathcal{R}_{0}=0$ ) final daily infection number $I_{S}^{d}(t)$ based on $v_{c}(t)$ curves with $R_{0}=2$ and $R_{0}=10$

Of course, our assumption is based on the fact that once lockdown measures are implemented in place, its removal is always smooth and gradually in reality, corresponding to smooth, steadily rising $n$th degree polynomial without any discontinuities. In fact, a steadily rising $n$th degree polynomial $\mathcal{R}_{c}(t)$ can render $\geq 1$ waves of infections as it returns to complete normalcy if $\mathcal{R}_{c}(t)$ exceeds the vaccination rate $V^{d}(t)$ at all times.

\section{Results}

\subsection{Israel Projections}

Israel uses Pfizer vaccine, with vaccine efficacy after the first dose to be $e_{1}=0.76$ and $e_{2}=0.9464$ to be the efficacy after the second dose, total population $N=9053000$, and $I(t)=796465[29,30,31]$. We obtain both time series for $V_{1}\left(t-t_{\epsilon}\right)$ and $V_{2}\left(t-t_{\epsilon}\right)$, where $t$ is March 5, 2021, and $t_{\epsilon}=8$ [32]. Hence, the immunity ratio curve for Israel is depicted in Figure 3.1. It is worth mentioning that the current weighted immunity achieved for Israel have just exceeded $50 \%$. 
medRxiv preprint doi: https://doi.org/10.1101/2021.03.25.21254362; this version posted March 26, 2021. The copyright holder for this preprint (which was not certified by peer review) is the author/funder, who has granted medRxiv a license to display the preprint in perpetuity.

It is made available under a CC-BY-NC-ND 4.0 International license .

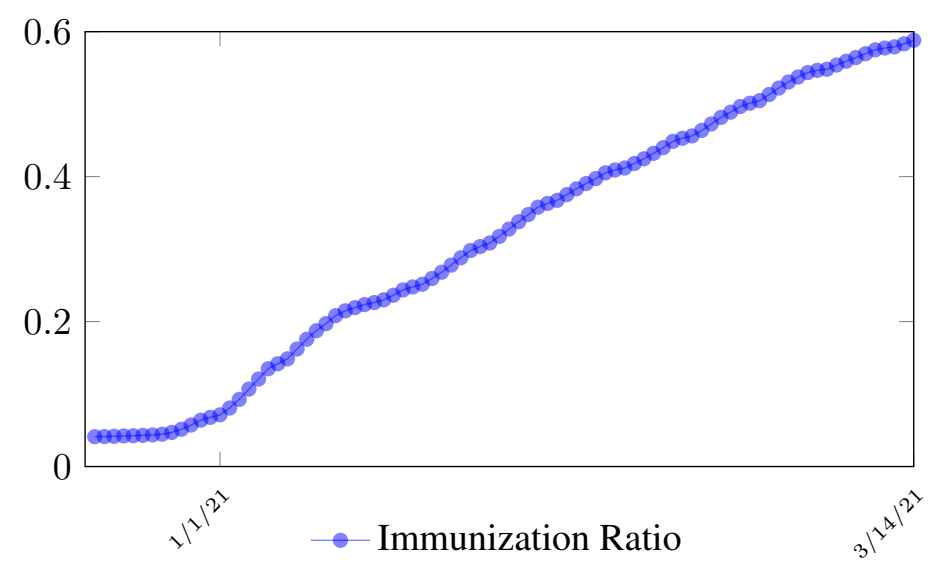

Figure 3.1: Israel effective immunization ratio

Figure 3.2 shows the final control reproduction number $\mathcal{R}_{c}(t)$ curve is a rising one, indicating that Israel, since the start of the vaccination, is experiencing the rising phase of a $\mathcal{R}_{c}(t)$ fluctuating cycle, which is justified since the population is relaxing too soon also and taking the advantage of the benefit of an increasingly immunized community.

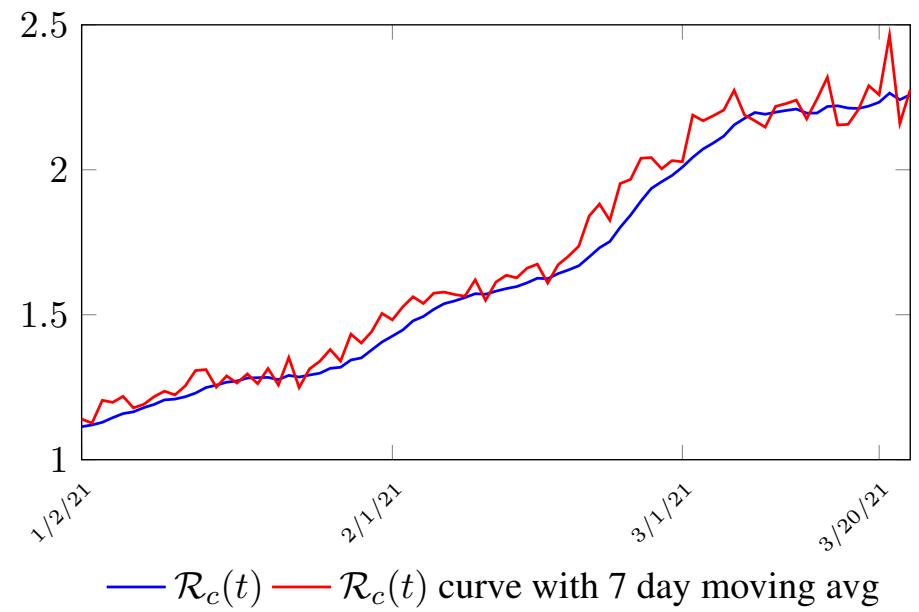

Figure 3.2: Israel's $\mathcal{R}_{c}(t)$ curve

It has a best fit of (when excluding data since March 2, 2021 because $\mathcal{R}_{c}(t)$ has finally peaked):

$$
\mathcal{R}_{c}(t)=0.0002386 t^{1.9783}+1.1521
$$

It is worth noting that the fit is an approximation of the final control reproduction number $\mathcal{R}_{c}(t)$ observed. Predictions can certainly deviates from reality, but it is forgivable as long as it is within the range of error of tolerance. The value of the intercept in equation (3.1) is the initial control reproduction number $\mathcal{R}_{c}$ for Israel at the beginning of vaccination program. In fact, if the same public health measures were continually maintained and respected, Our result shows that Israel could have seen the last COVID-19 case on February 12, 2021 (Figure 3.3).As we have assumed in our previous work with fixed $\mathcal{R}_{c}(t)$. [33] Although under such scenario, the border should remain closed since herd immunity is not yet achieved despite zero indigenous infections. Based on Israel's data, we know that COVID-19 variant strain has an intrinsic daily $\mathcal{R}_{0}$ value of at least $>2.2$, since the COVID-19 control $\mathcal{R}_{c}$ value has arisen to 2.2 on the latest day of observation. 
medRxiv preprint doi: https://doi.org/10.1101/2021.03.25.21254362; this version posted March 26, 2021. The copyright holder for this preprint (which was not certified by peer review) is the author/funder, who has granted medRxiv a license to display the preprint in perpetuity.

It is made available under a CC-BY-NC-ND 4.0 International license .

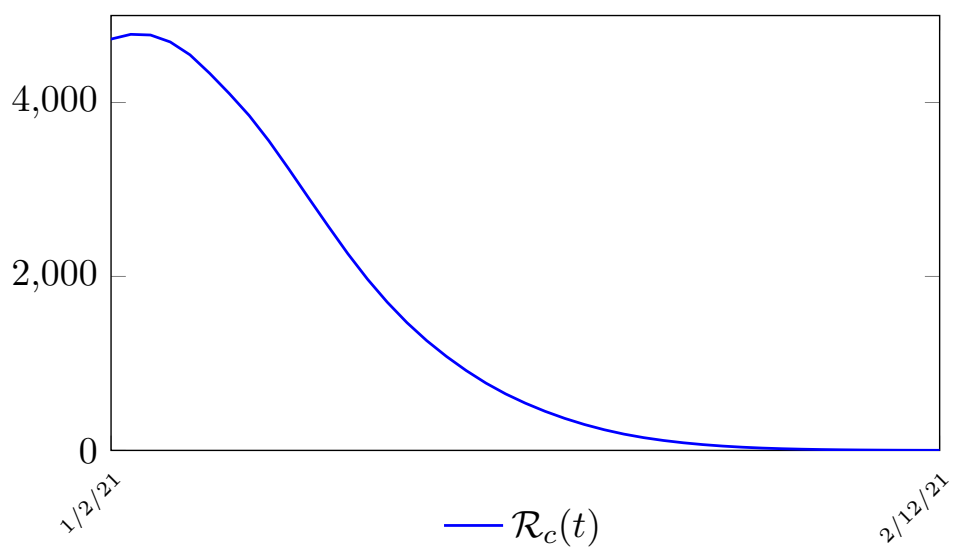

Figure 3.3: Israel's predicted daily infection if control $\mathcal{R}_{c}=1.1521$ remained.

Based on Israel's data, we cautiously conclude that COVID-19 variant strain has an intrinsic daily $\mathcal{R}_{0}$ value of 2.2, since the COVID-19 control $\mathcal{R}_{c}$ value has arisen to 2.2 since March 2, 2020 and no longer increase despite a continued relaxation of measures and starts to fall short from our $\mathcal{R}_{c}(t)$ projection in magnitudes as we never seen before (Figure 3.4).

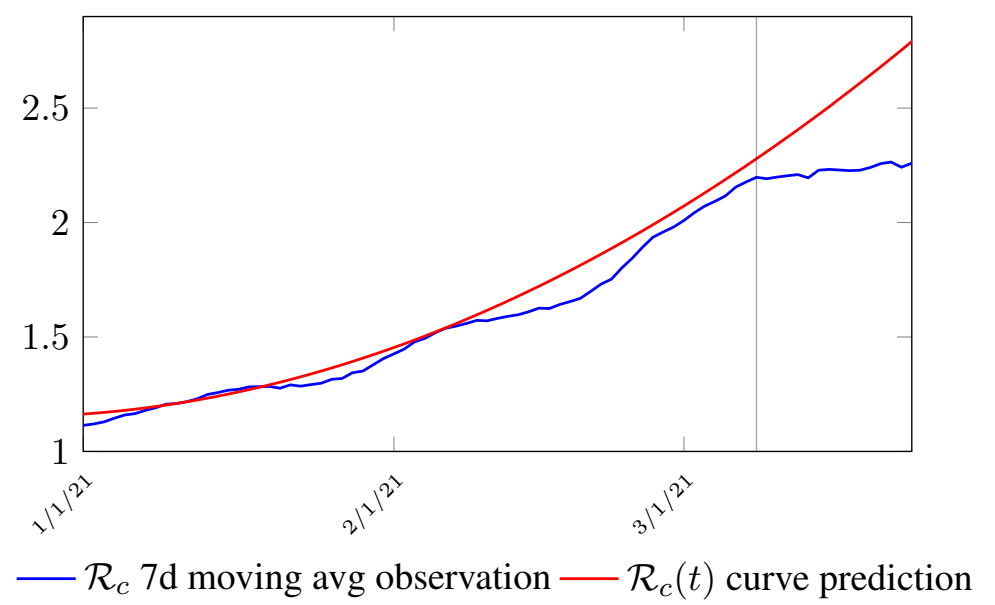

Figure 3.4: Observations starts to fall short from our $\mathcal{R}_{c}(t)$ projection. Previous observations had also fall short from $\mathcal{R}_{c}(t)$ projections, however, the gap has been much smaller, furthermore, the moving average was still increasing and not as a plateau as we observed now. The plateau starts at 3/8/21 indicated by the gray vertical divider.

In this case, we are lucky that the intrinsic $\mathcal{R}_{0}$ value can be measured, in which the vaccination program lasts long enough so that there is enough time for $\mathcal{R}_{c}(t)$ reaching its intrinsic ceiling value of $\mathcal{R}_{0}$ (but it may not always be the case). In fact, if the prediction holds, Israel will report its last case by early April, so the end of time window for prediction is just 3 weeks away. In order to extrapolate future trend, we need compute the vaccination rate $V_{1}^{d}(t)$ for 1 dose and vaccination rate $V_{2}^{d}(t)$ for 2 doses (Figure 3.5). Based on the past 1 month, no particular daily increase in single or double dose administration is observed [32]. Notice that by taking the 7 day moving average, one observe a 22 day delay between 1 st dose and the second dose administration. 
medRxiv preprint doi: https://doi.org/10.1101/2021.03.25.21254362; this version posted March 26, 2021. The copyright holder for this preprint (which was not certified by peer review) is the author/funder, who has granted medRxiv a license to display the preprint in perpetuity. It is made available under a CC-BY-NC-ND 4.0 International license .

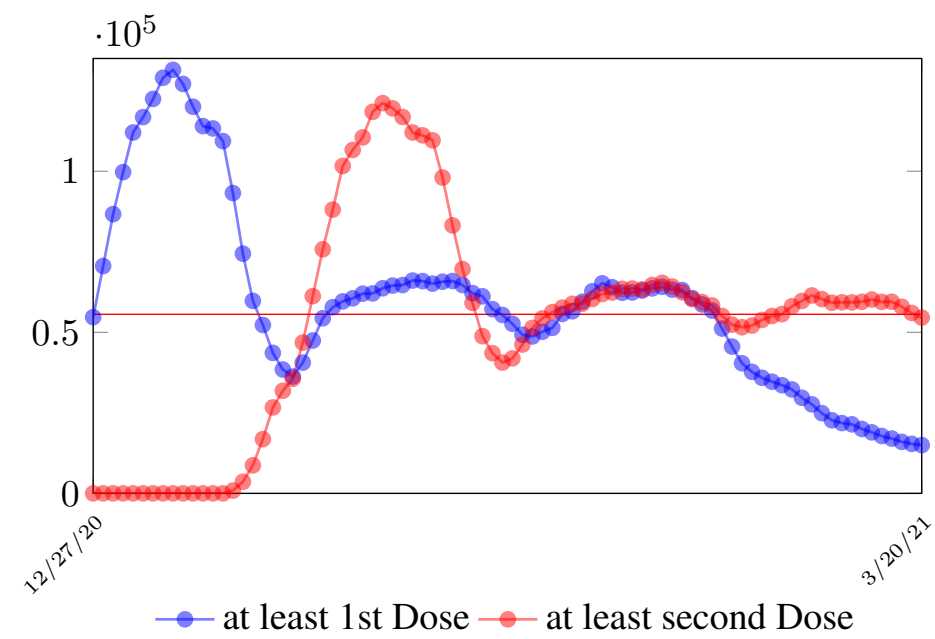

Figure 3.5: The observed Israel daily vaccination dosage administered for single and double doses during Feb 2021

As a result, we simply take the average dose administered during the month of February 2021 for single and double doses as the indicator for the vaccination rate of the future. So we have:

$$
\begin{gathered}
V_{1}^{d}(t)=55584 \\
V_{2}^{d}(t)=55584,
\end{gathered}
$$

where the average dosage delivered for both 1st and second dose are identical except with a time delay. So we have Israel's predictions in the upcoming months, the first simulation is assuming that the intrinsic $\mathcal{R}_{0} \geq \mathcal{R}_{c}\left(t_{L}\right)$. According to the simulation, when the last case is reported on April 29, of 2021, the final $\mathcal{R}_{c}\left(t_{L}\right)=4$.1. Based on our earlier discussion, if there exists $t_{0}$ in which $t_{F} \leq t_{0} \leq t_{L}$ that the intrinsic $\mathcal{R}_{0}$ is reached, then the predicted results for Israel would follow the other curves assuming $\mathcal{R}_{0}=2.5$ and $\mathcal{R}_{0}=3$ (Figure 3.6). The final $\mathcal{R}_{0}$ shall only be determined based upcoming results, for which we have to patiently wait for now. 
medRxiv preprint doi: https://doi.org/10.1101/2021.03.25.21254362; this version posted March 26, 2021. The copyright holder for this preprint (which was not certified by peer review) is the author/funder, who has granted medRxiv a license to display the preprint in perpetuity.

\section{It is made available under a CC-BY-NC-ND 4.0 International license .}

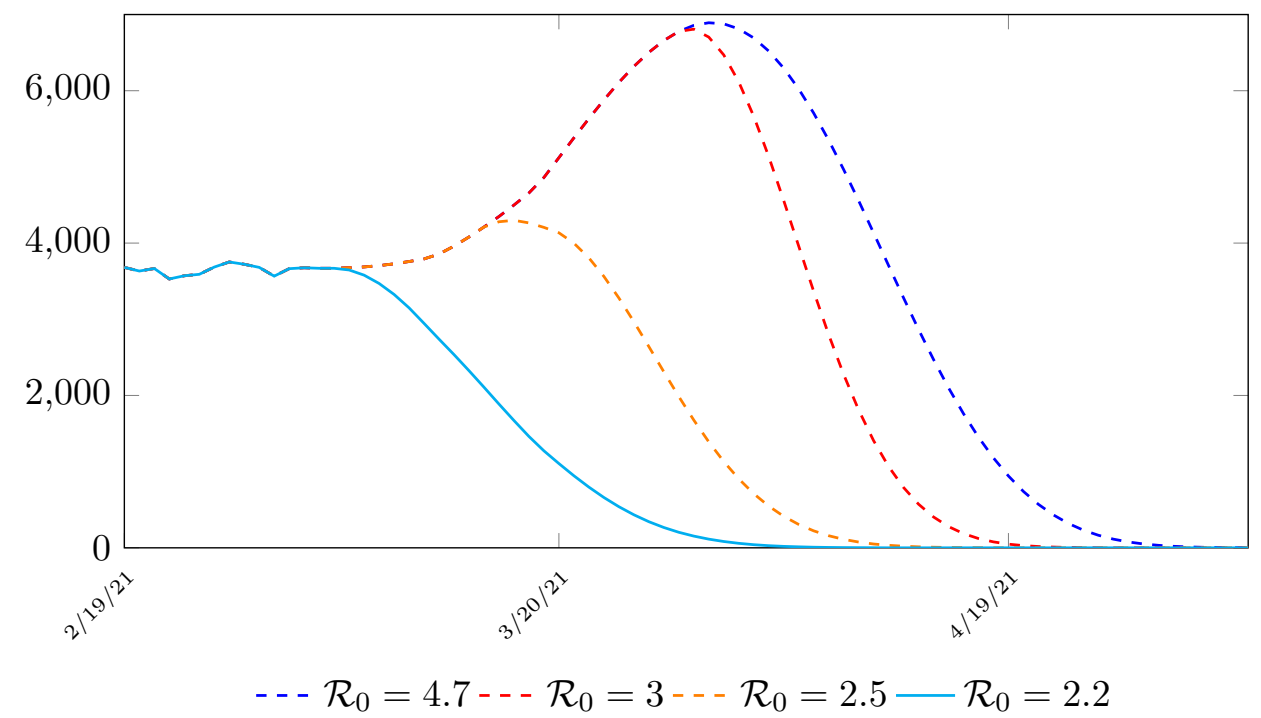

Figure 3.6: Israel predictions, left to right: $\mathcal{R}_{0}=2.2, \mathcal{R}_{0}=2.5, \mathcal{R}_{0}=3.0$, and $\mathcal{R}_{0}=4.7$. Its most likely that $\mathcal{R}_{0}=2.2$. Other trajectories given higher possible $\mathcal{R}_{0}$ is also shown. Notice that even for $\mathcal{R}_{0}=2.2$ trajectory is somewhat higher than the actual number of infection observed. This is reasonable since the curve is based on 7 day moving average.

\subsection{United States Projections}

Figure 3.7 depicts the 7 day moving average on the daily vaccination for at least a single and double dosages administered in United States [34].

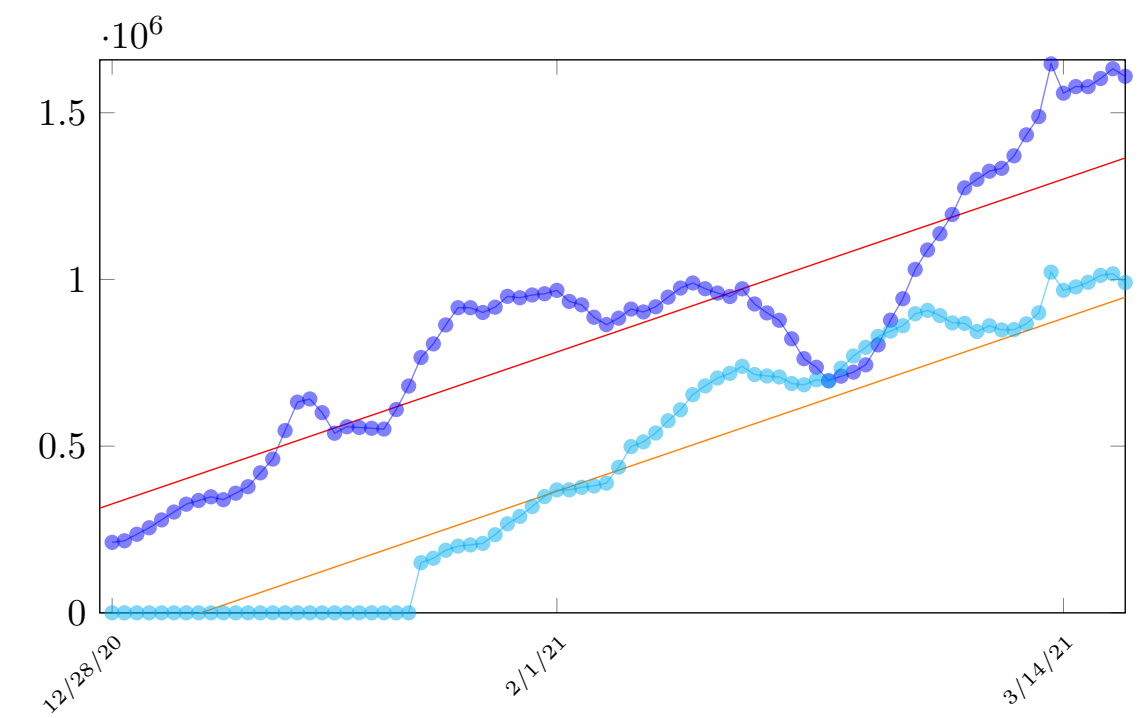

- Observed at least 1st dose - Observed at least 2nd Dose — Fit1 — Fit2

Figure 3.7: The 7 day moving average of US daily vaccination for dosage administered for at least 1 dose and its linear fit and at least 2 doses and its linear fit

We perform a linear fit for 1 st dose given by

$$
V_{1}^{d}(t)=12653 t+314070
$$


medRxiv preprint doi: https://doi.org/10.1101/2021.03.25.21254362; this version posted March 26, 2021. The copyright holder for this preprint (which was not certified by peer review) is the author/funder, who has granted medRxiv a license to display the preprint in perpetuity.

It is made available under a CC-BY-NC-ND 4.0 International license.

where the intercept 314070 is an over-estimation for vaccination administered record starting on Dec 28, 2020 and the second dose given by

$$
V_{2}^{d}(t)=12653(t-33)+314070
$$

which is not the best linear fit with least $R^{2}$, however, the idea behind such fit is simple. That is, there is a 1 month delay between all those had 1 st dose and the second dose. Other linear fits with lower $R^{2}$ leads to higher slopes and eventually overtake the daily increase of those had at least 1 dose, which is logically impossible. We then compute $E(t)$ and derived the immunization ratio of US as shown in Figure 3.8:

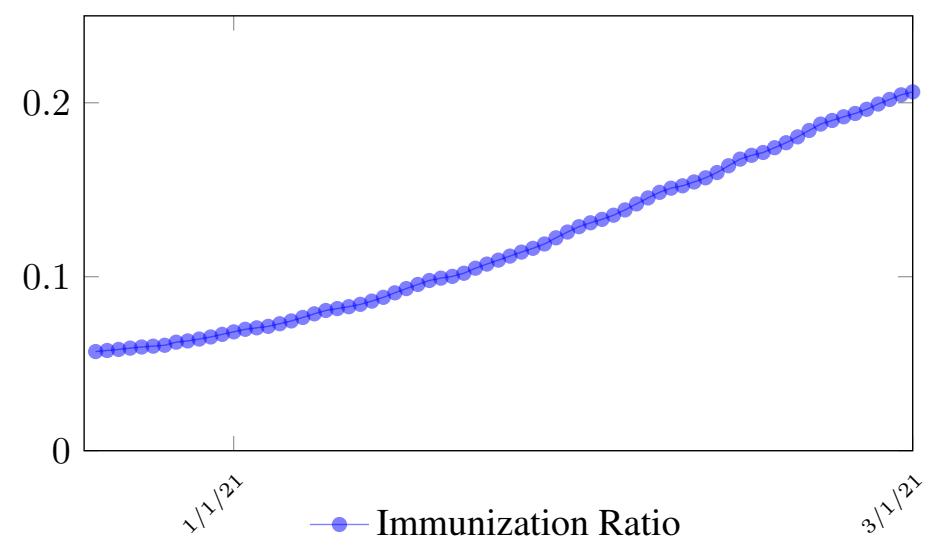

Figure 3.8: US effective immunization ratio

Figure 3.9 shows that the final $\mathcal{R}_{c}(t)$ curve is a rising one, indicating that US, since the start of the vaccination, is experiencing the rising phase of a $\mathcal{R}_{c}(t)$ fluctuating cycle, which is justified since the population is relaxing and taking the advantage of the benefit of an increasingly immunized community. 
medRxiv preprint doi: https://doi.org/10.1101/2021.03.25.21254362; this version posted March 26, 2021. The copyright holder for this preprint (which was not certified by peer review) is the author/funder, who has granted medRxiv a license to display the preprint in perpetuity.

It is made available under a CC-BY-NC-ND 4.0 International license .
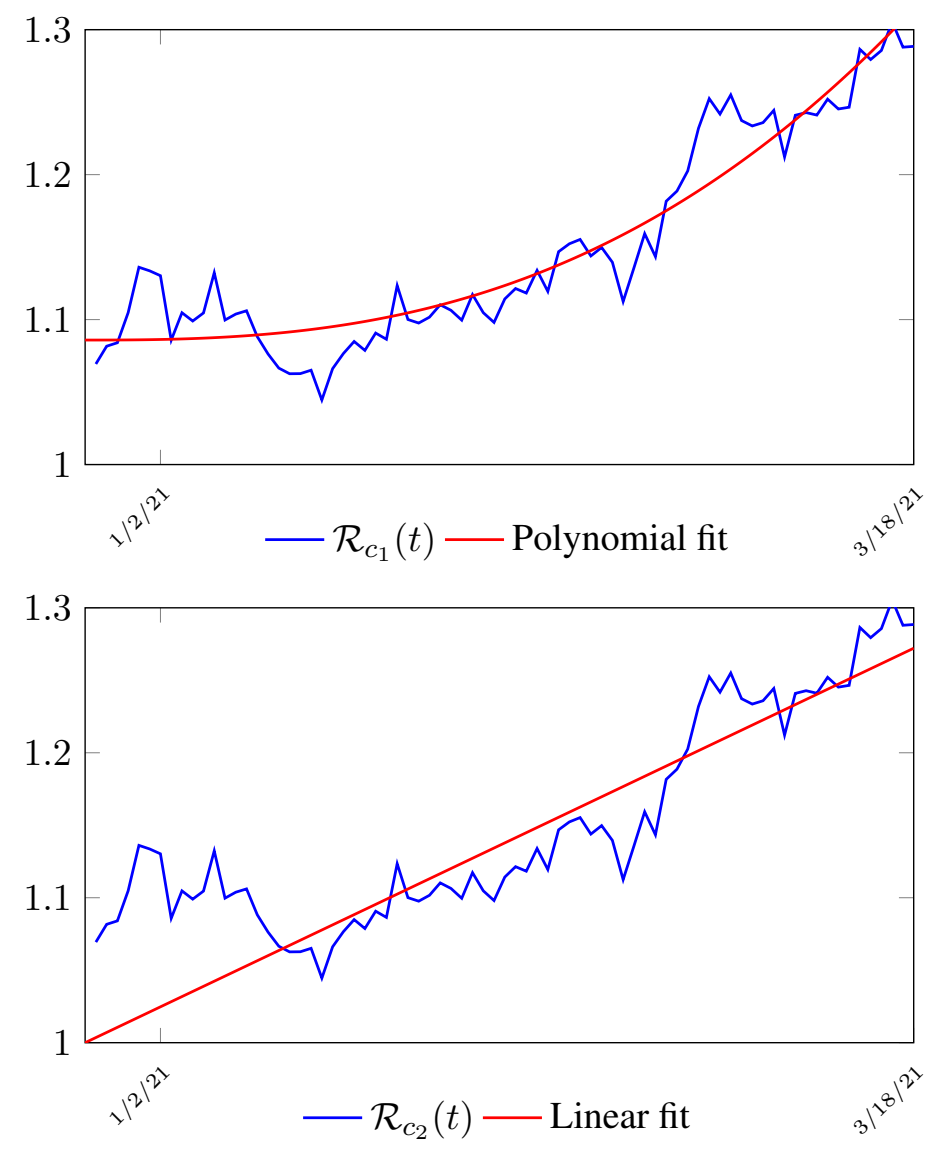

Figure 3.9: United States $\mathcal{R}_{c}(t)$ curve

We perform 2 fits for US, a polynomial and linear fit:

$$
\begin{gathered}
\mathcal{R}_{c_{1}}(t)=0.00000226 t^{2.653}+1.08589 \\
\mathcal{R}_{c_{2}}(t)=0.003533 t+1,
\end{gathered}
$$

where the intercept 1.0828 and 1 is the assumed initial control $\mathcal{R}_{c}$ value of US at the beginning of vaccination program. Along with $\mathcal{R}_{c}(t)$, we run the recursive simulation $S(t)$. We find that depending on the $\mathcal{R}_{c}(t)$ curve, and assuming $\mathcal{R}_{0}>2.2$, another surge of infection is imminent if the rising trend follows $\mathcal{R}_{c_{1}}(t)$. The vaccination rate will be too slow to catch up with the relaxation of human behaviors returning to normalcy, despite daily vaccination increase at a linear rate. With an initial infection size of 30,081,657 on March 14, 2021, additional infection of $6,101,698$ and cumulative effective vaccination size of 243,095,373 yields a cumulative effective immunization ratio $E(t)=0.867$ on June 30,2021 when $\mathcal{R}_{c}(t)=3.427$. Assuming $\mathcal{R}_{0}=2.2$, another surge still ensues but with somewhat faster decline, then additional infection of 5,624,152 and cumulative effective vaccination size of $216,944,672$ yields a cumulative effective immunization ratio $E(t)=0.784$ on Jun 19,2021 when $\mathcal{R}_{c}(t)=2.2$. If the rising trend follows $\mathcal{R}_{c_{2}}(t)$, one should observe a steady decreases of cases with a linear gradual return to normalcy with no additional surge and rebound. In that case, the last case is reported on May 15, 2021 when $\mathcal{R}_{c}(t)=1.495$ with additional infection of 706,952 and cumulative effective vaccination size of $143,813,093$ yields a cumulative effective immunization ratio $E(t)=0.542$. 


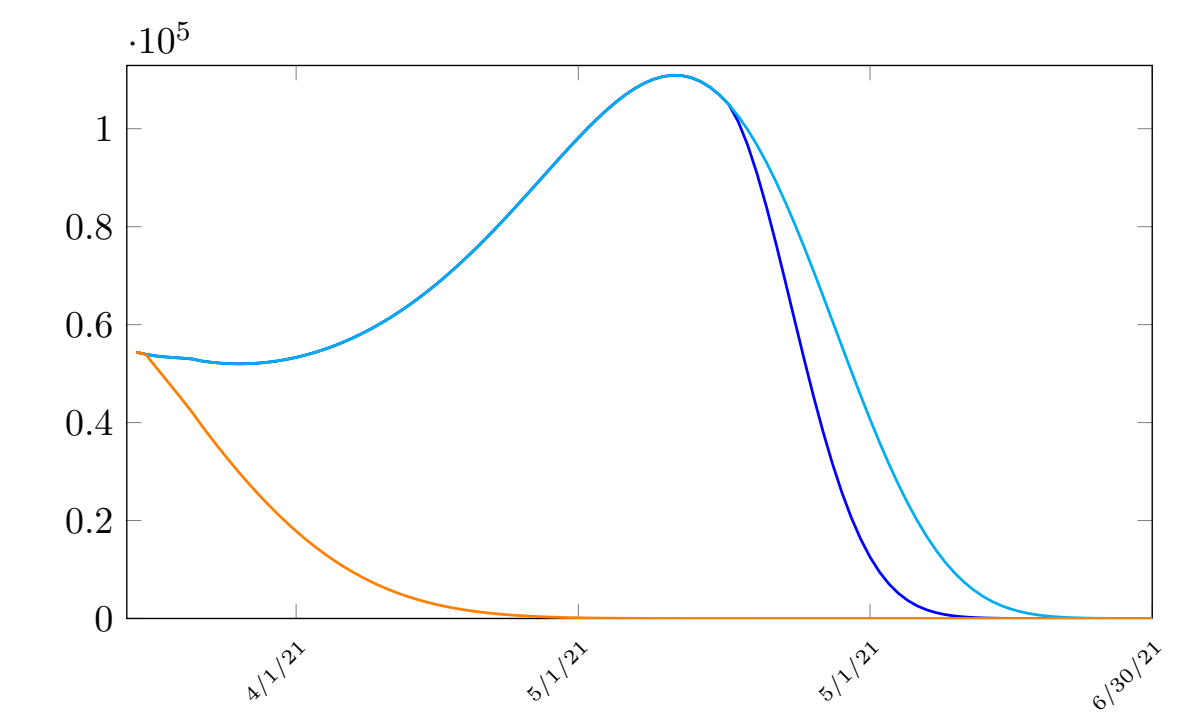

— Polynomial Fit with $\mathcal{R}_{c}=2.2 \_$Polynomial Fit with $\mathcal{R}_{c}>2.2 —$ Linear fit

Figure 3.10: US observed number of cases under 3 different trajectories

In all scenarios, zero additional cases are reported well before $t_{L}$, the assumed last day of total vaccination delivery is made when $E\left(t_{L}\right) \leq 1$. If human collective behavior changes in response to zero infection case achieved, and assuming that

$$
E(t)<1-\frac{1}{\mathcal{R}_{0}}
$$

That is, the endemic equilibrium is still higher than the cumulative effective immunization ratio achieved, then it is inevitable resurgence ensues with the imports of overseas cases, and a sudden discontinuity of positive jump on the $\mathcal{R}_{c}(t)$ over a short period of time. As a result, vaccination delivery must be continued and restrictive measures respected even if zero cases are reported. Under $\mathcal{R}_{c_{1}}(t)$ with a cumulative effective immunization ratio $E(t)=0.867$ and assuming in the worst case scenario in which $\mathcal{R}_{0} \rightarrow \infty$, then another 16 days of vaccination is required:

$$
\sum_{t=161}^{161+16}\left(V_{1}^{d}\left(t-t_{\epsilon}\right)-V_{2}^{d}\left(t-t_{\epsilon}\right)\right) \times e_{1}+\sum_{t=161}^{161+16} V_{2}^{d}\left(t-t_{\epsilon}\right) \times e_{2}=N(1-0.867),
$$

where $t=161$ is the number of days passed since Dec 27, 2020 when zero case is reported. That is, the pandemic ends in the US by July 16, 2021 if citizens collectively continue to respect measures in place and very gradually restores to normalcy even well after the last case is reported in June 30,2021 . Under $\mathcal{R}_{c_{2}}(t)$ scenario, which results a cumulative effective immunization ratio $E(t)=0.542$ when the last case is reported in May 15, then another 64 days of vaccination is required:

$$
\sum_{t=115}^{115+64}\left(V_{1}^{d}\left(t-t_{\epsilon}\right)-V_{2}^{d}\left(t-t_{\epsilon}\right)\right) \times e_{1}+\sum_{t=115}^{115+64} V_{2}^{d}\left(t-t_{\epsilon}\right) \times e_{2}=N(1-0.542),
$$

where $t=115$ is the number of days passed since Dec 27, 2020 when zero case is reported. That is, the pandemic officially ends in the US by July 18,2021 when $\mathcal{R}_{c_{2}}(t)=1.717$ if citizens collectively continue to respect measures in place and very gradually restores to normalcy even well after the last case is reported in May 15, 2021. Only when one assumes that $\mathcal{R}_{c_{1}}(t)$ with a cumulative effective immunization ratio $E(t)=0.784$ and assuming $\mathcal{R}_{0}=2.2$, 
medRxiv preprint doi: https://doi.org/10.1101/2021.03.25.21254362; this version posted March 26, 2021. The copyright holder for this preprint (which was not certified by peer review) is the author/funder, who has granted medRxiv a license to display the preprint in perpetuity. It is made available under a CC-BY-NC-ND 4.0 International license .

and $E(t)>1-\frac{1}{\mathcal{R}_{0}}$, then normalcy can be immediately restored as:

$$
\sum_{t=150}^{150}\left(V_{1}^{d}\left(t-t_{\epsilon}\right)-V_{2}^{d}\left(t-t_{\epsilon}\right)\right) \times e_{1}+\sum_{t=150}^{150} V_{2}^{d}\left(t-t_{\epsilon}\right) \times e_{2}=N(0.784),
$$

where $t=150$ is the number of days passed since Dec 27, 2020 when zero case is reported. That is, the pandemic ends in the US by June 19, 2021. Although, in this case, sporadic new imported cases can still be reported and causes local spread and quickly terminates without creating resurgence. The analysis shows that the battle against COVID-19 in US is no easier than 2020, a chance of resurgence is not only possible but possibly imminent unless people collectively remain cautious throughout the year despite a continually implemented vaccination program on a daily bases. That is, the administration of vaccine and even zero reported cases is by no means of a sign of relaxation and anxiety of returning to a complete normalcy, as long as the effective immunization ratio $E(t)<1$ and $\mathcal{R}_{0}$ value remains inconclusive.

\subsection{United Kingdom Projections}

During the month of March 2021, no particular daily increase in single dose administration is observed in UK (Figure 3.11) [35]. For the second dose, there is an increasing trend, but we shall conservatively assume that the trend will simply flat out. More interestingly, UK second dose does not follow the trend typically observed in other nations where the second dose administration typically follows the 1st dose with a 2 to 3 weeks delay.

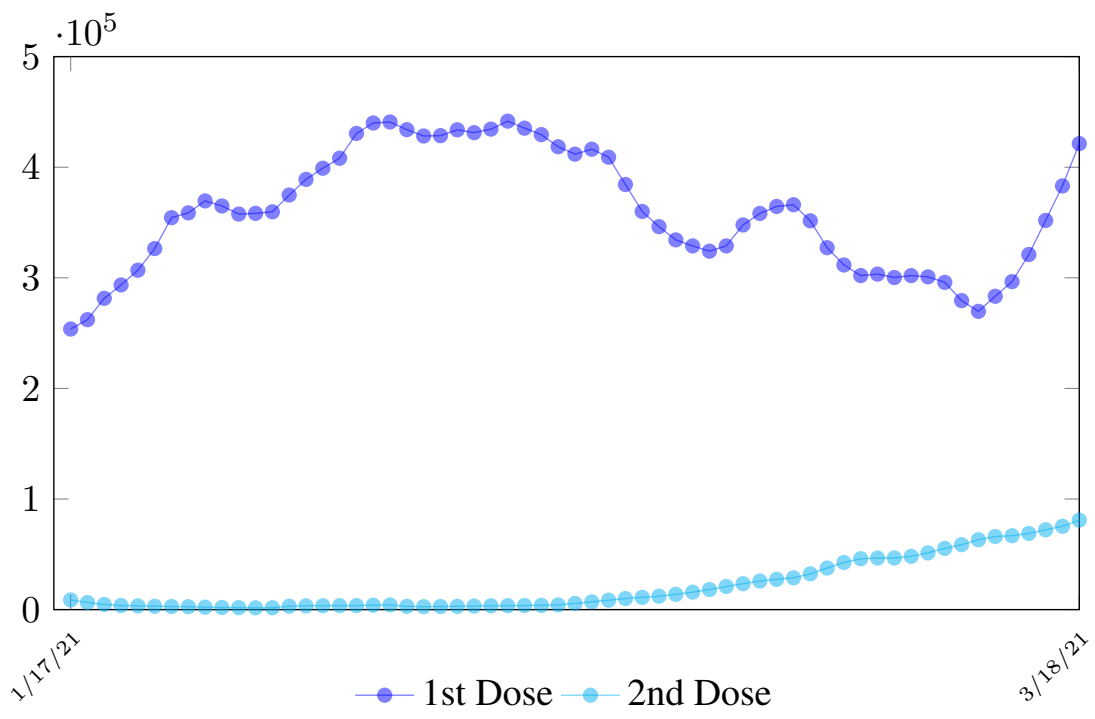

Figure 3.11: The observed UK daily vaccination dosage administered for at least single and at least double doses during late January to early March 2021

As a result, we simply take the average daily dose administered during late January to early March 2021 for single dose and average daily dose administered during the last 2 weeks of late February and early March 2021 for double doses as the indicator for the vaccination rate of the future. So we have:

$$
\begin{gathered}
V_{1}^{d}(t)=371512 \\
V_{2}^{d}(t)=50767
\end{gathered}
$$

We then compute $E(t)$ and derived the immunization ratio of UK as given in Figure 3.12 


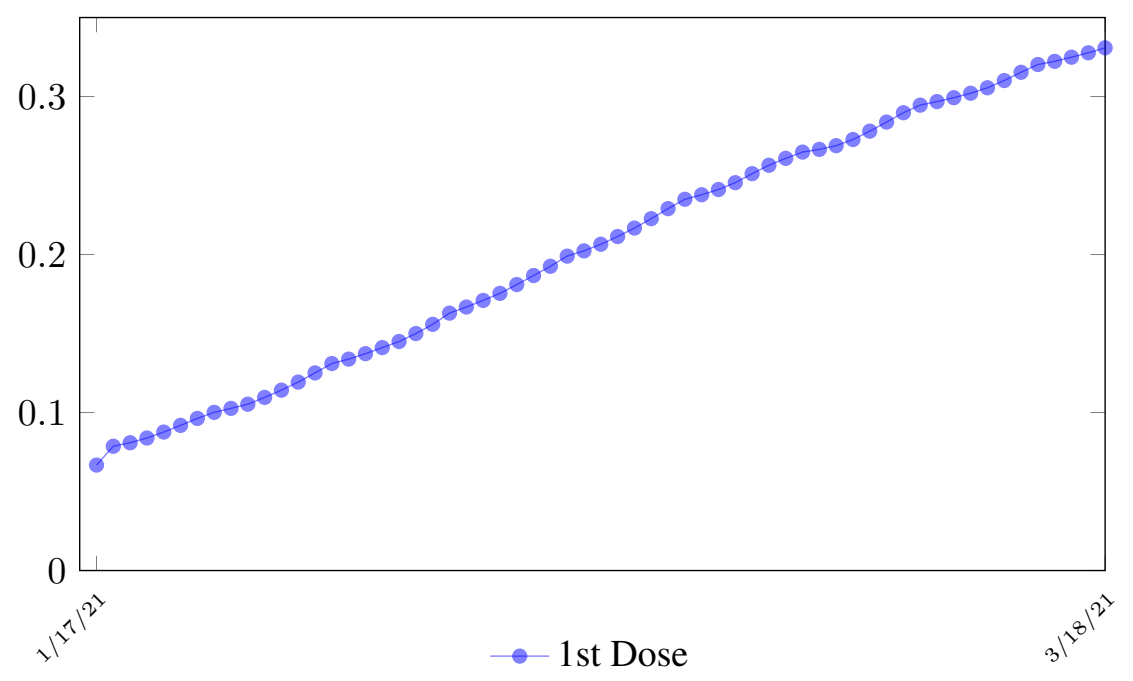

Figure 3.12: UK effective immunization ratio
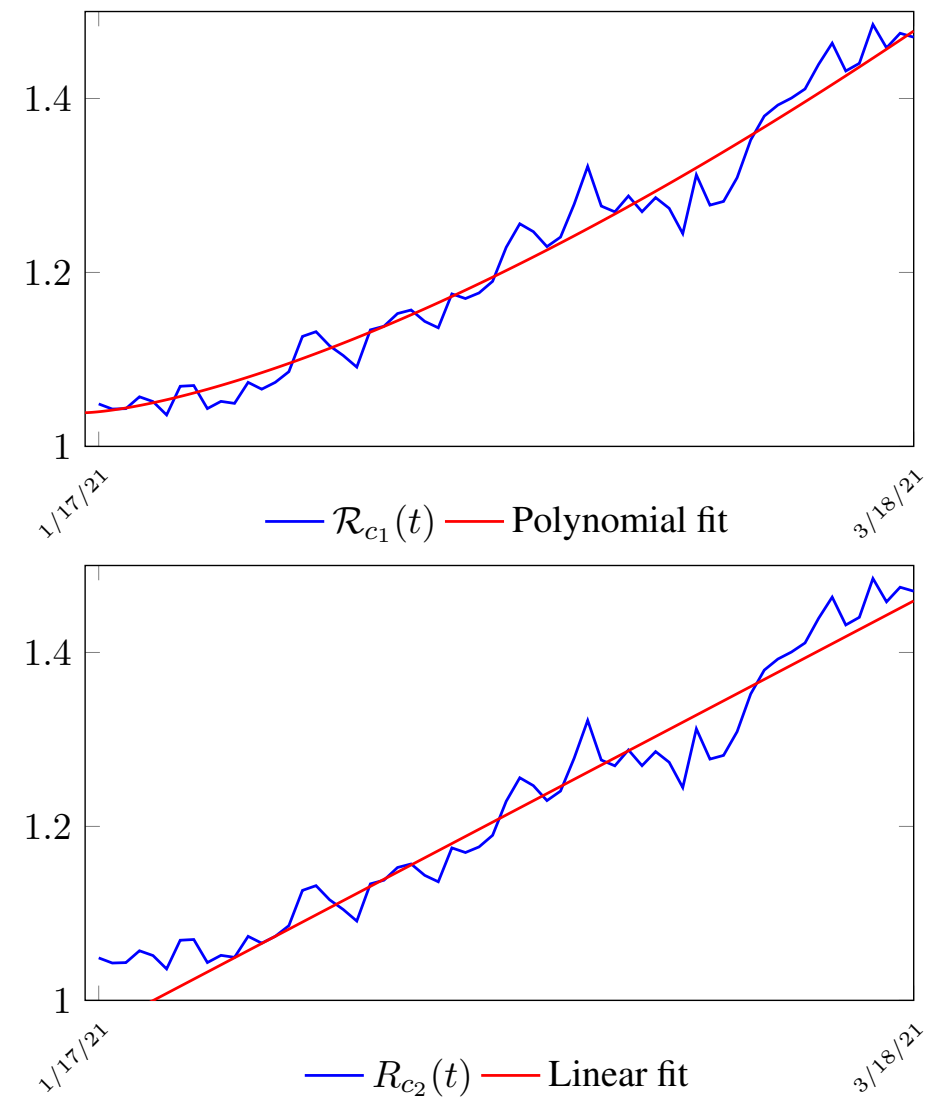

Figure 3.13: United Kingdom $R_{c}(t)$ curve

We perform 2 fits for UK, a polynomial and linear fit:

$$
\begin{gathered}
\mathcal{R}_{c_{1}}(t)=0.001091 t^{1.46}+1.0387 \\
\mathcal{R}_{c_{2}}(t)=0.0082 t+0.959
\end{gathered}
$$


medRxiv preprint doi: https://doi.org/10.1101/2021.03.25.21254362; this version posted March 26, 2021. The copyright holder for this preprint (which was not certified by peer review) is the author/funder, who has granted medRxiv a license to display the preprint in perpetuity.

It is made available under a CC-BY-NC-ND 4.0 International license .

where the intercept 1.03 is the initial control $\mathcal{R}_{c}$ value of UK at the beginning of vaccination program (Figure 3.13). Along with $\mathcal{R}_{c}(t)$, we run the recursive simulation $S(t)$. We find that depending on the $\mathcal{R}_{c}(t)$ curve, and assuming $\mathcal{R}_{0}>2.2$, no additional surge of infection is observed if the rising trend follows $\mathcal{R}_{c_{1}}(t)$. The vaccination rate is faster than the relaxation rate of human behaviors returning to normalcy. With an initial infection size of 4,285,684 on 3/19/21, [36, 37] additional infection of 183,799 and cumulative effective vaccination size of $38,115,429$ yields a cumulative effective immunization ratio $E(t)=0.735$ on June 17, 2021 (Figure 3.14) when $\mathcal{R}_{c}(t)=2.766$. If the rising trend follows $\mathcal{R}_{c_{1}}(t)$, one should also observe a faster steady decreases of cases with a linear gradual return to normalcy with no additional surge and rebound. In that case, the last case is reported on May 25, 2021 when $\mathcal{R}_{c}(t)=2.017$ yields a cumulative effective immunization ratio $E(t)=0.6334$.

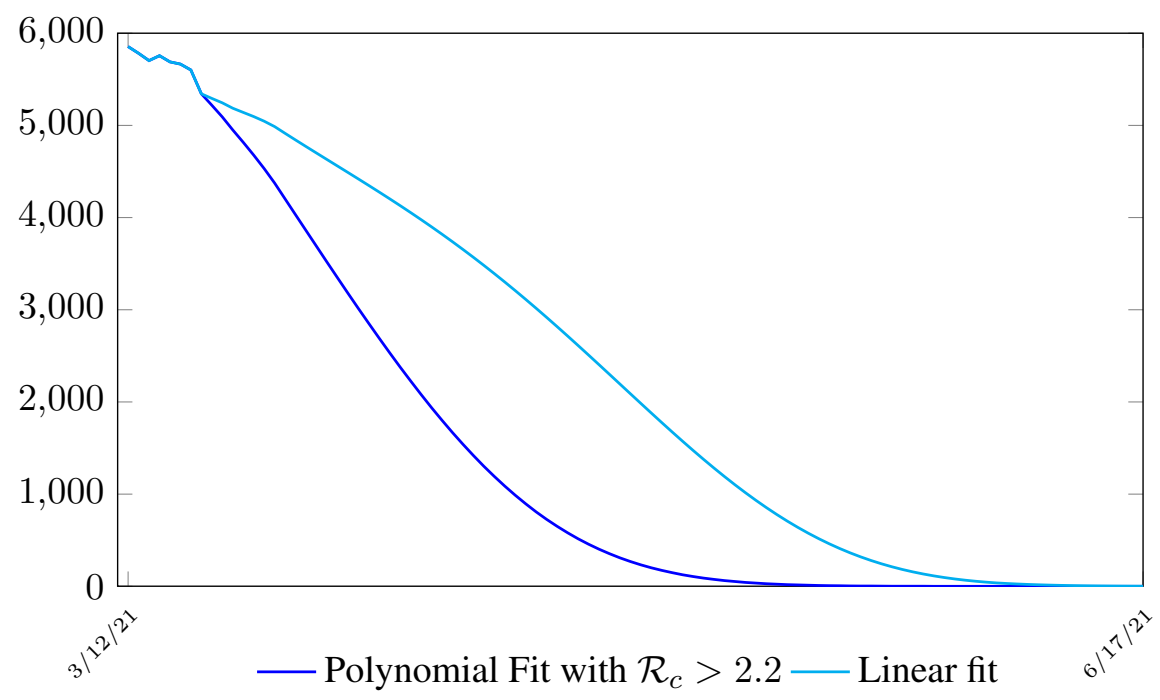

Figure 3.14: UK observed number of cases under 2 different $\mathcal{R}_{c}(t)$ curve

In all scenarios, zero additional cases are reported well before $t_{L}$, the assumed last day of total vaccination delivery is made when $E\left(t_{L}\right) \leq 1$. If human collective behavior changes in response to zero infection case achieved, and assuming that

$$
E(t)<1-\frac{1}{\mathcal{R}_{0}}
$$

That is, the endemic equilibrium is still higher than the cumulative effective immunization ratio achieved, then it is inevitable resurgence ensues with the imports of overseas cases, and a sudden discontinuity of positive jump on the $\mathcal{R}_{c}(t)$ over a short period of time. As a result, vaccination delivery must be continued and restrictive measures respected even if zero cases are reported. Under $\mathcal{R}_{c_{1}}(t)$ with a cumulative effective immunization ratio $E(t)=0.735$ and assuming in the worst case scenario in which $\mathcal{R}_{0} \rightarrow \infty$, then another 16 days of vaccination is required:

$$
\sum_{t=98}^{98+60}\left(V_{1}^{d}\left(t-t_{\epsilon}\right)-V_{2}^{d}\left(t-t_{\epsilon}\right)\right) \times e_{1}+\sum_{t=98}^{98+60} V_{2}^{d}\left(t-t_{\epsilon}\right) \times e_{2}=N(1-0.735)
$$

Whereas $t=98$ is the number of days passed since Mar 12, 2021 when zero case is reported. That is, the pandemic ends in the UK no later than September 24, 2021 if citizens collectively continue to respect measures in place and very gradually restores to normalcy even well after the last case is reported in June 17, 2021.

Under $\mathcal{R}_{c_{2}}(t)$ scenario, which results a cumulative effective immunization ratio $E(t)=0.6334$ when the last 
medRxiv preprint doi: https://doi.org/10.1101/2021.03.25.21254362; this version posted March 26, 2021. The copyright holder for this preprint (which was not certified by peer review) is the author/funder, who has granted medRxiv a license to display the preprint in perpetuity.

It is made available under a CC-BY-NC-ND 4.0 International license .

case is reported in May 15, then another 64 days of vaccination is required:

$$
\sum_{t=75}^{75+83}\left(V_{1}^{d}\left(t-t_{\epsilon}\right)-V_{2}^{d}\left(t-t_{\epsilon}\right)\right) \times e_{1}+\sum_{t=75}^{75+83} V_{2}^{d}\left(t-t_{\epsilon}\right) \times e_{2}=N(1-0.6334)
$$

Whereas $t=75$ is the number of days passed since Mar 12, 2021 when 0 case is reported. That is, the pandemic officially ends in the UK by $9 / 24 / 21$ when $\mathcal{R}_{c_{2}}(t)=2.73$ if citizens collectively continue to respect measures in place and very gradually restores to normalcy even well after the last case is reported in 5/25/21.

The reason that in both cases the pandemic ends on the same date is that the difference between the infections under $\mathcal{R}_{c_{1}}(t)$ and $\mathcal{R}_{c_{2}}(t)$ with the latest observed date until the 0 reported cases into the future based on simulation is minimal so that

$$
\sum_{t=0}^{98} I_{1}^{d}(t)-\sum_{t=0}^{75} I_{2}^{d}(t) \leq\left(V_{1}^{d}\left(158-t_{\epsilon}\right)-V_{2}^{d}\left(158-t_{\epsilon}\right)\right) e_{1}+V_{2}^{d}\left(158-t_{\epsilon}\right) e_{2}
$$

it is less than the daily vaccination rate at day $158-t_{\epsilon}$, so any difference is compensated within a single day. In general, a pandemic ends $n_{2}$ days faster under $\mathcal{R}_{c_{1}}(t)$ when $t_{E 1}$ is the last day of infection reported under $\mathcal{R}_{c_{1}}(t)$. $t_{E 1}>t_{E 2}, n_{1}$ is the additional days required for $E(t)=1$ under $\mathcal{R}_{c_{1}}(t)$ after $t_{E 1} \cdot n_{1}+n_{2}$ is the additional days needed for $E(t)=1$ under $\mathcal{R}_{c_{2}}(t)$ after $t_{E 2}$.

$$
\sum_{t=0}^{t_{E 1}} I_{1}^{d}(t)-\sum_{t=0}^{t_{E 2}} I_{2}^{d}(t)=\sum_{t=0}^{t_{E 2}+n_{1}+n_{2}}\left(\left(V_{1}^{d}\left(t-t_{\epsilon}\right)-V_{2}^{d}\left(t-t_{\epsilon}\right)\right) e_{1}+V_{2}^{d}\left(t-t_{\epsilon}\right) e_{2}\right)
$$

\subsection{Serbia Projections}

Based on all historical records, no particular daily increase in single or double dose administration is observed in Serbia, [38] and the second dose administration lags behind the 1st by 17 days, as typically observed in Israel and US as in Figure 3.15 .

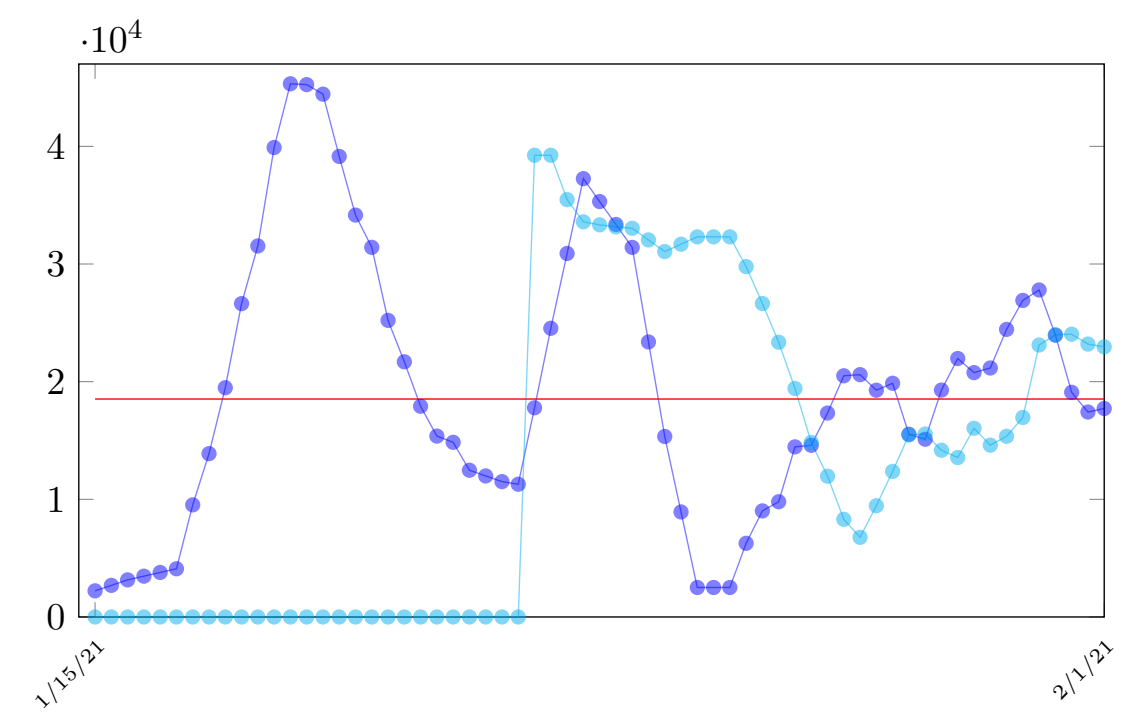

$\_$Observed at least 1 st dose $\_$Observed at least second Dose — Fit1

Figure 3.15: The 7 day moving average of Serbia daily vaccination for dosage administered for at least 1 dose and at least 2 doses 
medRxiv preprint doi: https://doi.org/10.1101/2021.03.25.21254362; this version posted March 26, 2021. The copyright holder for this preprint (which was not certified by peer review) is the author/funder, who has granted medRxiv a license to display the preprint in perpetuity.

It is made available under a CC-BY-NC-ND 4.0 International license .

As a result, we simply take the average daily dose administered during the entire 2021 for single dose and average daily dose administered during the last 1 month from Feb to March 2021 for double doses as the indicator for the vaccination rate of the future. So we have:

$$
\begin{aligned}
& V_{1}^{d}(t)=18524 \\
& V_{2}^{d}(t)=18524
\end{aligned}
$$

We then compute $E(t)$ and derived the immunization ratio of Serbia as given in (Figure 3.16)

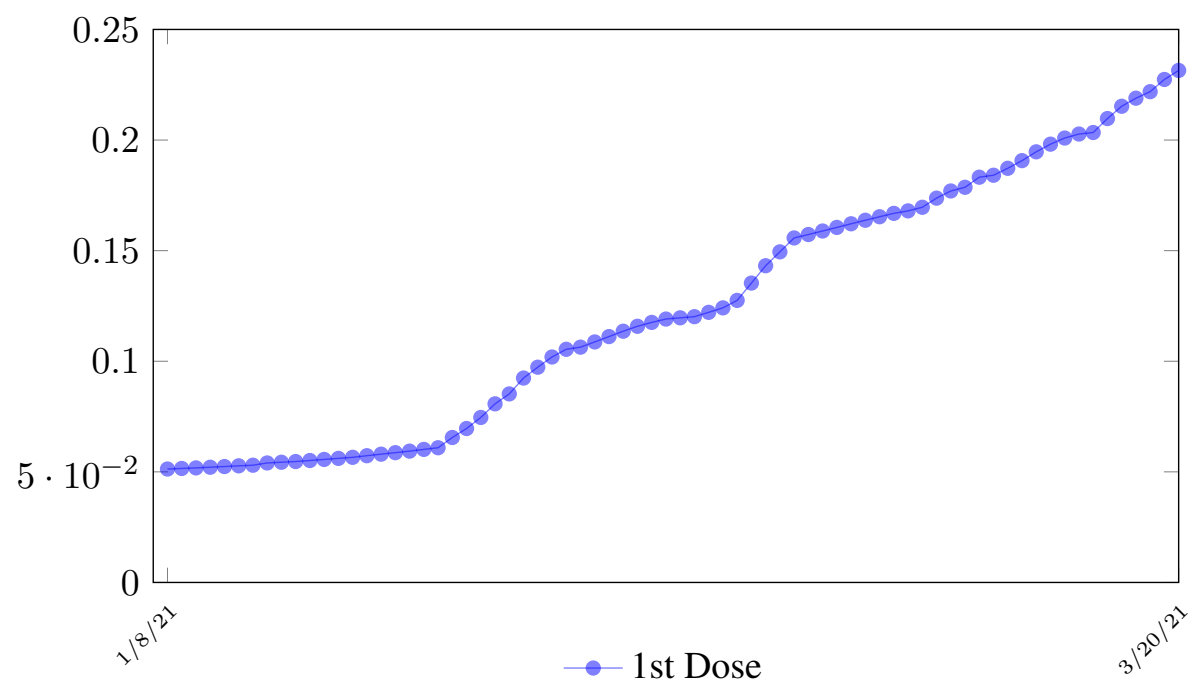

Figure 3.16: Serbia effective immunization ratio

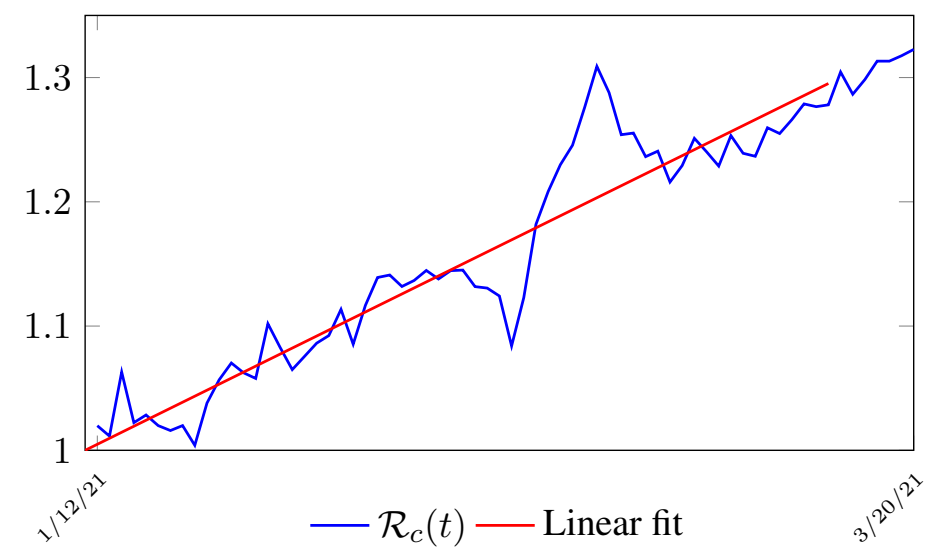

Figure 3.17: Serbia $\mathcal{R}_{c}(t)$ curve

We perform 2 fits for Serbia, a polynomial and linear fit, but polynomial fit is actually sub-linear so we have a single linear fit:

$$
\mathcal{R}_{c}(t)=0.0048 t+1,
$$

where the intercept 1 is the initial control $\mathcal{R}_{c}$ value of Serbia at the beginning of vaccination program.

Along with $\mathcal{R}_{c}(t)$, we run the recursive simulation $S(t)$. We find that depending on the $\mathcal{R}_{c}(t)$ curve, and assuming $\mathcal{R}_{0}>2.2$, a small surge of infection is observed if the rising trend follows $\mathcal{R}_{c}(t)$ (Figure 3.17). The 
medRxiv preprint doi: https://doi.org/10.1101/2021.03.25.21254362; this version posted March 26, 2021. The copyright holder for this preprint (which was not certified by peer review) is the author/funder, who has granted medRxiv a license to display the preprint in perpetuity.

It is made available under a CC-BY-NC-ND 4.0 International license .

vaccination rate is somewhat slower than the relaxation rate of human behaviors returning to normalcy. With an initial infection size of 546,896 on 3/20/21, [39] [40] additional infections of 357,628 and cumulative effective vaccination size of $6,561,999$ yields a cumulative effective immunization ratio $E(t)=0.5817$ on July 18,2021 when $\mathcal{R}_{c}(t)=1.9$. (Figure 3.18).

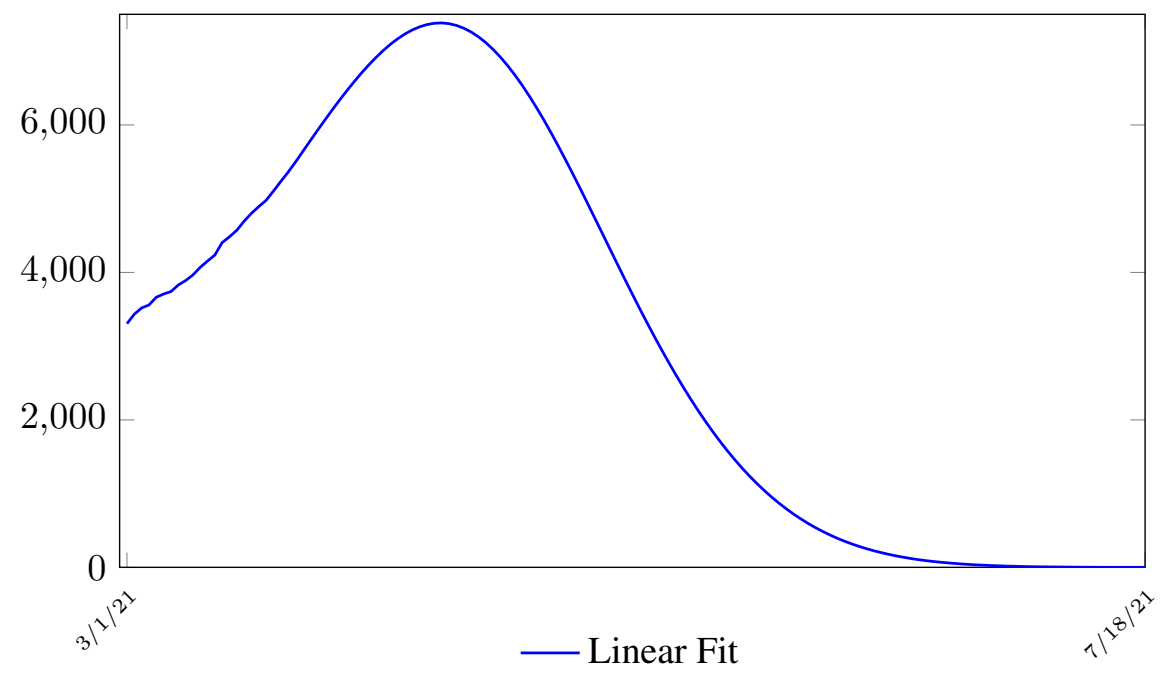

Figure 3.18: Serbia observed number of cases under $\mathcal{R}_{c}(t)$ curve

zero additional cases are reported well before $t_{L}$, the assumed last day of total vaccination delivery is made when $E\left(t_{L}\right) \leq 1$. If human collective behavior changes in response to 0 infection case achieved, and assuming that

$$
E(t)<1-\frac{1}{\mathcal{R}_{0}}
$$

That is, the endemic equilibrium is still higher than the cumulative effective immunization ratio achieved, then it is inevitable resurgence ensues with the imports of overseas cases, and a sudden discontinuity of positive jump on the $\mathcal{R}_{c}(t)$ over a short period of time. As a result, vaccination delivery must be continued and restrictive measures respected even if zero cases are reported. Under $\mathcal{R}_{c}(t)$ with a cumulative effective immunization ratio $E(t)=0.5871$ and assuming in the worst case scenario in which $\mathcal{R}_{0} \rightarrow \infty$, then another 164 days of vaccination is required:

$$
\sum_{t=140}^{140+164}\left(V_{1}^{d}\left(t-t_{\epsilon}\right)-V_{2}^{d}\left(t-t_{\epsilon}\right)\right) \times e_{1}+\sum_{t=140}^{140+164} V_{2}^{d}\left(t-t_{\epsilon}\right) \times e_{2}=T(1-0.5871)
$$

Whereas $t=140$ is the number of days passed since Mar 1st, 2021 when zero case is reported. That is, the pandemic ends in Serbia no later than 12/29/21 if citizens collectively continue to respect measures in place and very gradually restores to normalcy even well after the last case is reported in 7/18/21.

\section{Discussion}

The relationship between $t_{\epsilon}$, the delay of the onset of antibodies after immunization, and $e_{1}$, the efficiency for inducing antibodies based immunity with at least one dose requires further analysis. In our paper, we assumed there is a 8 days delay for the onset of antibodies after immunization. However, other literature suggests a range of delays [29]. There are two possible assumptions. First, $e_{1}$ can remain fixed while the delay is lengthened to $t_{\epsilon}+t_{d}$. In this case, the final immunity ratio $E(t)$ decreases because $V_{1}\left(t-\left(t_{\epsilon}+t_{d}\right)\right)$ :

$$
E(t)=\frac{I(t)+\left(V_{1}\left(t-\left(t_{\epsilon}+t_{d}\right)\right)\right) \times e_{1}+\ldots}{N}
$$


medRxiv preprint doi: https://doi.org/10.1101/2021.03.25.21254362; this version posted March 26, 2021. The copyright holder for this preprint (which was not certified by peer review) is the author/funder, who has granted medRxiv a license to display the preprint in perpetuity.

It is made available under a CC-BY-NC-ND 4.0 International license .

Second, $e_{1}$ is increased to $e_{1}+e_{d}$ while the delay is lengthened to $t_{\epsilon}+t_{d}$. In this case, it suggests that our previous delay was too short to cover all possible cases with induced immunity. The final $E(t)$ is then depending on the magnitude of $e_{d}$ and $t_{d}$ as:

$$
E(t)=\frac{I(t)+\left(V_{1}\left(t-\left(t_{\epsilon}+t_{d}\right)\right)\right) \times\left(e_{1}+e_{d}\right)+\ldots}{N}
$$

The second case led to us to the conclusion that both models are approximations. In reality, the number of immunized increases in a time dependent manner. In the simplest form, the cumulative number of people with induced immunity grows linearly with each passing day from a pool of people initially vaccinated. If the daily newly induced is constant, then a uniform distribution spread across time can model daily changes. Then, weighted average delay $t_{\epsilon}$ is:

$$
t_{\epsilon}=\frac{1}{n}\left(\frac{n(n+1)}{2}\right)=\frac{n+1}{2}
$$

assuming in $n$ days all possible induced immunization is realized and each day shares $\frac{1}{n}$ out of all induced. One can easily see in that case the final $t_{\epsilon}$ should be the median of $n$ days registered. In reality, each passing day likely to have weighted proportion, and non-uniform distribution such as normal distribution spread across time can probably model daily changes more accurately. In such case, the cumulative number of people with induced immunity grows according to a logistic function. In general, assume there is a function $F\left(V_{1}(t), t+t_{i}\right)$ that takes initial size of people vaccinated on day $t$ and given a subsequent day $t+t_{i}$, returns the number of people with induced immunity on day $t+t_{i}$. Then the weighted average delay $t_{\epsilon}$ can be computed as:

$$
t_{\epsilon}=\sum_{t_{i}=0}^{n} \frac{F\left(V_{1}(t), t+t_{i}\right) \times t_{i}}{V_{1}(t)}
$$

However, weighted average delay $t_{\epsilon}$ is yet another approximation attempt at its best. To truly represent the number of people with induced immunity one has to construct a $\left(t_{L}-t_{F}\right)\left(t_{L}-t_{F}+n+1\right)$ sized matrix $A$ as:

$$
\boldsymbol{A}=\left(\begin{array}{cccc}
\boldsymbol{V}_{\mathbf{1}}\left(\boldsymbol{t}_{\boldsymbol{F}}\right) & \boldsymbol{V}_{\mathbf{1}}\left(\boldsymbol{t}_{\boldsymbol{F}}+\mathbf{1}\right) & \ldots & \sum(\boldsymbol{t}) \\
F\left(V_{1}\left(t_{F}\right), t_{F}+1\right) & 0 & \ldots & F\left(V_{1}\left(t_{F}\right), t_{F}+1\right) \\
F\left(V_{1}\left(t_{F}\right), t_{F}+2\right) & F\left(V_{1}\left(t_{F}+1\right), t_{F}+2\right) & \ldots & \sum_{t_{i}=0}^{1} F\left(V_{1}\left(t_{F}+t_{i}\right), t_{F}+2\right) \\
F\left(V_{1}\left(t_{F}\right), t_{F}+3\right) & F\left(V_{1}\left(t_{F}+1\right), t_{F}+3\right) & \ldots & \sum_{t_{i}=0}^{2} F\left(V_{1}\left(t_{F}+t_{i}\right), t_{F}+3\right) \\
F\left(V_{1}\left(t_{F}\right), t_{F}+4\right) & F\left(V_{1}\left(t_{F}+1\right), t_{F}+4\right) & \ldots & \sum_{t_{i}=0}^{3} F\left(V_{1}\left(t_{F}+t_{i}\right), t_{F}+4\right) \\
F\left(V_{1}\left(t_{F}\right), t_{F}+5\right) & F\left(V_{1}\left(t_{F}+1\right), t_{F}+5\right) & \ldots & \sum_{t_{i}=0}^{4} F\left(V_{1}\left(t_{F}+t_{i}\right), t_{F}+5\right) \\
\ldots & F\left(V_{1}\left(t_{F}+1\right), t_{F}+6\right) & \ldots & \sum_{t_{i}=0}^{5} F\left(V_{1}\left(t_{F}+t_{i}\right), t_{F}+6\right) \\
\ldots & \ldots & \ldots & \ldots \\
F\left(V_{1}\left(t_{F}\right), t_{F}+n\right) & F\left(V_{1}\left(t_{F}+1\right), t_{F}+n\right) & \ldots & \sum_{t_{i}=0}^{n-1} F\left(V_{1}\left(t_{F}+t_{i}\right), t_{F}+n\right) \\
0 & F\left(V_{1}\left(t_{F}+1\right), t_{F}+(n+1)\right) & \ldots & \sum_{t_{i}=1}^{n} F\left(V_{1}\left(t_{F}+t_{i}\right), t_{F}+(n+1)\right) \\
0 & 0 & \ldots & \sum_{t_{i}=2}^{n+1} F\left(V_{1}\left(t_{F}+t_{i}\right), t_{F}+(n+2)\right) \\
\ldots & \ldots & \ldots & \ldots \\
0 & 0 & \ldots & \sum_{t_{i}=0}^{n-1} F\left(V_{1}\left(t_{L}+t_{i}\right), t_{L}+n\right)
\end{array}\right)
$$

Whereas the final results are tallied under the last row $\boldsymbol{A}\left[t_{L}-t_{F}+1\right]$, and $V_{1}(t) \times e_{1}$ can be re-defined as the cumulative of all with induced immunity from vaccinations from all days:

$$
V_{1}(t) \times e_{1}=\sum_{j=0}^{t} \boldsymbol{A}\left[t_{L}-t_{F}+1\right][j]
$$


medRxiv preprint doi: https://doi.org/10.1101/2021.03.25.21254362; this version posted March 26, 2021. The copyright holder for this preprint (which was not certified by peer review) is the author/funder, who has granted medRxiv a license to display the preprint in perpetuity. It is made available under a CC-BY-NC-ND 4.0 International license .

and daily effective vaccination can be defined as:

$$
V_{1}^{d}(t) \times e_{1}=\boldsymbol{A}\left[t_{L}-t_{F}+1\right][t]
$$

Correspondingly, similar matrix can be constructed for the second dose. This certainly leaves room for future work to make predictions more precise.

Finally, the relationship diagram for deriving $\mathcal{R}_{c}$, the control $\mathcal{R}_{0}$ can be illustrated as below:

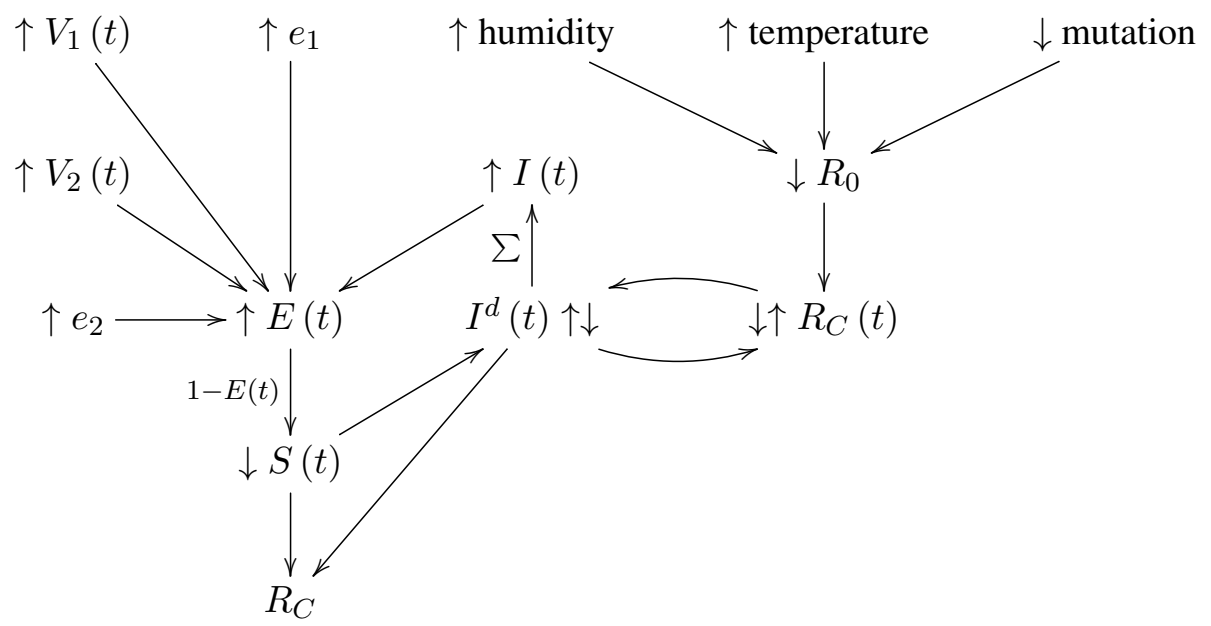

That is, the intrinsic $\mathcal{R}_{0}$ can be altered as the humidity, temperature, and mutate variation of the virus changes. Based on the intrinsic $\mathcal{R}_{0}, \mathcal{R}_{c}(t) \leq \mathcal{R}_{0}$ can be derived which changes through time. That is, the community as a whole follows cycles of relaxation and restrictive measures depends on the observed daily infection. When the infection numbers $I^{d}(t)$ are high, the observant community resorts to more cautious behavior. Which in turn reduces $\mathcal{R}_{c}(t)$ and lower $I^{d}(t)$ is observed. $\mathcal{R}_{c}(t)$ is not the only factor influences $I^{d}(t)$. The remaining susceptible population ratio $S(t)$ also plays a role in shaping the final numbers of $I^{d}(t)$. The the summation of $I^{d}(t)$ leads to cumulative number of infection $I(t)$. At the same time, the daily vaccination number $V_{1}(t)$, the efficacy $e_{1}$, the daily vaccination number $V_{2}(t)$, the efficacy $e_{2}$, and cumulative number of infection $I(t)$ leads to immunity ratio $E(t)$, which leads to the remaining susceptible population ratio $S(t)=1-E(t)$. Finally, $\mathcal{R}_{c}$ at the current time can be derived based on the rate of change in $I^{d}(t)$ and $S(t)$ leads computed, this is how we arrived at the conclusion that COVID-19 has at least a daily $\mathcal{R}_{0} \geq 2.2$.

\section{Conclusions}

Israel currently observed $\mathcal{R}_{0}=2.2$ is a very encouraging value, it implies that the pandemic can possibly terminate sooner than most expect [41] [21]. However, very few countries have reached the level of effective immunization to corroborate the validity of this result other than Seychelles. Seychelles has a much lower population at 100,000 but considerable infections at the current time so that its $\mathcal{R}_{c}(t)$ can be measured. However, $\mathcal{R}_{c}(t)$ of Seychelles has so far not yet plateau and $\mathcal{R}_{c}(t)>2.2$. Many explanations can be given, illustrated as a table below.

\begin{tabular}{ccc} 
Israel & \multicolumn{2}{c}{ Other Regions } \\
& True & False \\
\hline True & $(1)$ & $(2)$ \\
& $\mathcal{R}_{0}=2.2$ & $\mathcal{R}_{0}=2.2$ \\
& $\mathcal{R}_{0}=2.2$ & $\mathcal{R}_{0} \neq 2.2$ \\
False & N/A & $(3)$ \\
& & $\mathcal{R}_{0} \neq 2.2$ \\
& & $\mathcal{R}_{0} \neq 2.2$ \\
\hline
\end{tabular}


medRxiv preprint doi: https://doi.org/10.1101/2021.03.25.21254362; this version posted March 26, 2021. The copyright holder for this preprint (which was not certified by peer review) is the author/funder, who has granted medRxiv a license to display the preprint in perpetuity.

It is made available under a CC-BY-NC-ND 4.0 International license .

It is possible that $\mathcal{R}_{0}=2.2$ is indigenous to Israel only as case (2). Seychelles has a higher $\mathcal{R}_{0}$ due to locally higher level of social interaction and different viral strains. Since Seychelles has received a mix dosage of vaccines not limited Pfizer, it is possible that the difference in $\mathcal{R}_{0}$ is due to differential efficacy of the vaccines. It is also possible that $\mathcal{R}_{0}>2.2$. The currently observed value in Israel is still not the intrinsic $\mathcal{R}_{0}$ due to continued partial social distancing measures in place as suggested under (3). More analysis is required in the future as more countries reaching full effective immunization ratio. The $\mathcal{R}_{0}$ calculation can be replaced by the matrix tabulation we mentioned prior to gain better precision. However, it does not undermine our current assessment, as long as one adopt the identical methodology on computing $\mathcal{R}_{0}$ across all data. Finally, even assuming $\mathcal{R}_{0}>2.2$, due to aggressive vaccination program, continued implementation of restrictive measures, or both, in all countries we have analyzed present an optimistic outlook at controlling the pandemic toward the latter part of 2021.

\section{References}

[1] CGTN, “"Six COVID-19 vaccine candidates in phase-3 trials, 3 from China: WHO”," (Aug 2020). Online Version

[2] N. news, “"'Russia's fast-track coronavirus vaccine draws outrage over safety”," (Aug 2020). Online Version

[3] Medicines and H. products Regulatory Agency, "“Vaccine BNT162b2 - Conditions of authorisation under Regulation 174 - 2"," (December 2, 2020).

[4] B. Mueller, ““'U.K. Approves Pfizer Coronavirus Vaccine, a First in the West”, " New York Times (December 2, 2020).

[5] E. Commission, “"'Questions and Answers: COVID-19 vaccination in the EU”," (Jan 2021). Online Version

[6] G. News, “'”AE: Ministry of Health announces 86 per cent vaccine efficacy”," (Dec 2020). Online Version

[7] B. N. Agency, "'Bahrain second in the world to approve the Pfizer/BioNTech Covid-19 vaccine"," (Dec 2020).

Online Version

[8] CNBC, “'”DDA approves second Covid vaccine for emergency use as it clears Moderna's for U.S. distribution"," (Dec 2020).

Online Version

[9] C. N. Ngonghala, E. Iboi, S. Eikenberry, M. Scotch, C. R. MacIntyre, M. H. Bonds, and A. B. Gumel, "“"Mathematical assessment of the impact of non-pharmaceutical interventions on curtailing the 2019 novel coronavirus,"," Mathematical Biosciences (108364) (2020).

[10] C. N. Ngonghala, E. Iboi, and A. B. Gumel, ““'Could masks curtail the post-lockdown resurgence of covid-19 in the US?"," Mathematical Biosciences (108452) (2020).

[11] S. E. Eikenberry, M. Muncuso, E. Iboi, T. Phan, E. Kostelich, Y. Kuang, and A. B. Gumel, ““'To mask or not to mask: Modeling the potential for face mask use by the general public to curtail the COVID-19 pandemic"," Infectious Disease Modeling (293-308) (2020).

[12] J. Hellewell, S. Abbott, A. Gimma, N. I. Bosse, C. I. Jarvis, T. W. Russell, J. D. Munday, A. J. Kucharski, W. J. Edmunds, and F. S. et al., "“Feasibility of controlling COVID-19 outbreaks by isolation of cases and contacts"," The Lancet Global Health (E488-E496) (2020). 
medRxiv preprint doi: https://doi.org/10.1101/2021.03.25.21254362; this version posted March 26, 2021. The copyright holder for this preprint (which was not certified by peer review) is the author/funder, who has granted medRxiv a license to display the preprint in perpetuity. It is made available under a CC-BY-NC-ND 4.0 International license .

[13] A. J. Kucharski, T. W. Russell, C. Diamond, Y. Liu, J. Edmunds, R. M. E. S. Funk, F. Sun, M. Jit, and J. D. Munday, “"Early dynamics of transmission and control of covid-19: a mathematical modelling study", The Lancet Infectious Diseases (553-558) (2020).

[14] L. Xue, S. Jing, J. C. Miller, W. Sun, H. Li, J. G. Estrada-Franco, J. M. Hyman, and H. Zhu, ““'A datadriven network model for the emerging covid-19 epidemics in Wuhan, Toronto and Italy"," Mathematical Biosciences (108391) (2020).

[15] J. A. Firth, J. Hellewell, P. Klepac, and S. Kissler, ““'Using a real-world network to model localized covid-19 control strategies"," Nature Medicine (2020).

[16] N. M. Ferguson, D. Laydon, G. Nedjati-Gilani, N. Imai, K. Ainslie, M. Baguelin, S. Bhatia, A. Boonyasiri, Z. Cucunuba, G. Cuomo-Dannenburg, and et al., "“'Impact of non-pharmaceutical interventions (NPIs) to reduce COVID-19 mortality and healthcare demand, London: Imperial College COVID-19 Response Team"," (March 16 2020).

[17] N. M. Ferguson, D. Laydon, G. Nedjati-Gilani, N. Imai, K. Ainslie, M. Baguelin, S. Bhatia, A. Boonyasiri, Z. Cucunuba, G. Cuomo-Dannenburg, and et al., "“Impact of non-pharmaceutical interventions (NPIs) to reduce COVID-19 mortality and healthcare demand, London: Imperial College COVID-19 Response Team"," (March 16 2020).

[18] A. Srivastava and G. Chowell., “"'Understanding spatial heterogeneity of COVID-19 pandemic using shape analysis of growth rate curves"," medRxiv (2020).

[19] I. C.-. health service utilization forecasting team, "“Forecasting COVID-19 impact on hospital bed-days, ICU-days, ventilator-days and deaths by us state in the next 4 months"," medRxiv (2020).

[20] Y. L. A. Tariq, K. Roosa, S. Blumberg, P. Yan, S. Ma, and G. Chowell, "“Real-time monitoring the transmission potential of COVID-19 in Singapore, march 2020"," BMC Medicine 18 (1-14) (2020).

[21] A. B. Gumel, E. A. Iboi, C. N. Ngonghala, and E. H. Elbasha, ““"A primer on using mathematics to understand COVID-19 dynamics: Modeling, analysis and simulations",' Infectious Disease Modelling (Nov 14, 2020).

[22] S. S. Zhu, ““The Predictions on Worldwide Covid-19 Pandemic Cases Based on Historical Data”, ' Researchgate (May 2020).

[23] S. S. Zhu, ““'Optimal Strategies for Covid-19 Vaccination Policies based on All Possible Mathematical Landscapes and the Outlook for 2021 with a Special Case Study for Serbia"," Researchgate (Dec 2020).

[24] S. S. Zhu, ““'A Generalized Viral Infection Mathematical Model Derived from Covid-19 Simulation”," Researchgate (Oct 2020).

[25] S. CEG., ““'Prospects of the control of disease”,” Proc Roy Soc Med (pg. 1181-90) (1970).

[26] C. K. Dietz K. Ludwig D, ““'Transmission and control of arbovirus diseases”,” Epidemiology, Philadelphia PASociety for Industrial and Applied Mathematics (pg. 104-21) (1975).

[27] S. S. Zhu, “The Mathematics Behind Covid-19 and Viral Infections” (Oct 2020).

[28] S. S. Zhu, ““'The Cyclic Nature of Covid-19's Daily Diagnoses and its Mathematical Modeling based on Infection Cycles from Both Temporal and Spatial Aspects"," Researchgate (Aug 2020).

[29] Pfizer and BioNTech, ““FDA Briefing Document: Pfizer-BioNTech COVID-19 Vaccine/Cumulative Incidence Curves for the First COVID-19 Occurrence After Dose 1, Dose 1 All-Available Efficacy Population",' Vaccines and Related Biological Products Advisory Committee Meeting (December 10, 2020). 
medRxiv preprint doi: https://doi.org/10.1101/2021.03.25.21254362; this version posted March 26, 2021. The copyright holder for this preprint (which was not certified by peer review) is the author/funder, who has granted medRxiv a license to display the preprint in perpetuity.

It is made available under a CC-BY-NC-ND 4.0 International license .

[30] Worldometer, “’”Israel Coronavirus Case”," (March 2021).

Online Version

[31] Wikipedia, “"'COVID-19 pandemic in Israel”," (March 2021).

Online Version

[32] E. Mathieu, “"’owid/covid-19-data”," (March 2021).

Online Version

[33] A. B. Gumel, E. Iboi, C. Ngonghala, C. Ngonghala, and G. A. Ngwa, ““'Mathematical assessment of the roles of vaccination and non-pharmaceutical interventions on COVID-19 dynamics: a multigroup modeling approach"," medRxiv (Dec, 2020).

[34] E. Mathieu, “"'owid/covid-19-data”," (March 2021).

Online Version

[35] E. Mathieu, “"”owid/covid-19-data”," (March 2021).

Online Version

[36] Worldometer, “"'United Kingdom Coronavirus Case"," (March 2021).

Online Version

[37] Wikipedia, “"'COVID-19 pandemic in UK”," (March 2021).

Online Version

[38] E. Mathieu, “"owid/covid-19-data”," (March 2021), https://github.com/owid/ covid-19-data/blob/master/public/data/vaccinations/country_data/Serbia. csv, Sidst set 03/2021.

[39] Worldometer, “"'Serbia Coronavirus Case”," (March 2021).

Online Version

[40] Wikipedia, “"COVID-19 pandemic in Serbia”," (March 2021).

Online Version

[41] J. AXELROD, "Coronavirus may infect up to 70 percent of world's population, expert warns," .

Online Version 